\title{
Nogo-A Inhibits Neurite Outgrowth and Cell Spreading with Three Discrete Regions
}

\author{
Thomas Oertle, ${ }^{1 *}$ Marjan E. van der Haar, ${ }^{1 *}$ Christine E. Bandtlow, ${ }^{2}$ Anna Robeva, ${ }^{3}$ Patricia Burfeind, ${ }^{3}$ Armin Buss, ${ }^{1}$ \\ Andrea B. Huber, ${ }^{1}$ Marjo Simonen, ${ }^{1}$ Lisa Schnell, ${ }^{1}$ Christian Brösamle, ${ }^{1}$ Klemens Kaupmann, ${ }^{4}$ Rüdiger Vallon, ${ }^{3}$ and \\ Martin E. Schwab ${ }^{1}$ \\ ${ }^{1}$ Brain Research Institute, University of Zurich, and Department of Biology, Swiss Federal Institute of Technology, CH-8057 Zurich, Switzerland, ${ }^{2}$ Institute \\ of Medical Chemistry and Biochemistry, Leopold-Franzens-University of Innsbruck, A-6020 Innsbruck, Austria, ${ }^{3}$ Novartis Institute for Biomedical \\ Research, Functional Genomics, Novartis Pharmaceuticals Corporation, Summit, New Jersey 07901, and ${ }^{4}$ Novartis Pharma AG, Nervous System Research, \\ CH-4002 Basel, Switzerland
}

Nogo-A is a potent neurite growth inhibitor in vitro and plays a role both in the restriction of axonal regeneration after injury and in structural plasticity in the CNS of higher vertebrates. The regions that mediate inhibition and the topology of the molecule in the plasma membrane have to be defined. Here we demonstrate the presence of three different active sites: (1) an N-terminal region involved in the inhibition of fibroblast spreading, (2) a stretch encoded by the Nogo-A-specific exon that restricts neurite outgrowth and cell spreading and induces growth cone collapse, and (3) a C-terminal region (Nogo-66) with growth cone collapsing function. We show that Nogo-Aspecific active fragments bind to the cell surface of responsive cells and to rat brain cortical membranes, suggesting the existence of specific binding partners or receptors. Several antibodies against different epitopes on the Nogo-A-specific part of the protein as well as antisera against the 66 aa loop in the C-terminus stain the cell surface of living cultured oligodendrocytes. Nogo-A is also labeled by nonmembrane-permeable biotin derivatives applied to living oligodendrocyte cultures. Immunofluorescent staining of intracellular, endoplasmic reticulum-associated Nogo-A in cells after selective permeabilization of the plasma membrane reveals that the epitopes of Nogo-A, shown to be accessible at the cell surface, are exposed to the cytoplasm. This suggests that Nogo-A could have a second membrane topology. The two proposed topological variants may have different intracellular as well as extracellular functions.

Key words: Nogo; reticulon; inhibitory regions; active sites; membrane topology; neurite outgrowth

\section{Introduction}

Regenerative nerve fiber growth and structural plasticity are limited in the adult mammalian CNS, in part because of the presence of neurite growth inhibitory constituents (Schwab and Bartholdi, 1996; Behar et al., 2000). An important step in elucidating the mechanisms mediating this inhibition was the molecular characterization of nogo- $A$, which encodes an oligodendrocyte-

\footnotetext{
Received July 30, 2002; revised April 14, 2003; accepted April 15, 2003.

This study was supported by the Swiss National Science Foundation (Grant 31-63633) and by the Spinal Cord Consortium of the Christopher Reeve Paralysis Foundation, Springfield, NJ. We thank B. Haudenschild, T. Flego, F. Christ, B. Niederöst, and C. Huber for excellent technical assistance, Dr. B. Martoglio for helpful discussions, and R. Schöb for help with the figures. Special thanks to Dr. M. Zurini (Novartis Pharma) for HPLC purification and PreScission cleavage of GST-Nogo-66 and Superdex Gel filtration of NiG, Dr. B. Sommer (Novartis Pharma) for hNogo-A CDNA, Dr. M. Chao for kindly providing us with the APtag5 vector, and Dr. R. Giger for providing us with the AP-Sema3A vector.

${ }^{*}$ T.O. and M.E.V. contributed equally to this work.

Correspondence should be addressed to Thomas Oertle, Department of Biology, Swiss Federal Institute of Technology Zurich and Brain Research Institute, University of Zurich, CH-8057 Zurich, Switzerland. E-mail: oertle@hifo.unizh.ch.

A. B. Huber's present address: Department of Neuroscience, The Johns Hopkins School of Medicine, Baltimore MD, 21205.

M. Simonen's present address: Novartis Pharma AG, CH-4002 Basel, Switzerland.

C. Brösamle's present address: Department of Embryology, Carnegie Institution of Washington, Baltimore MD, 21210.

Copyright $\odot 2003$ Society for Neuroscience $\quad$ 0270-6474/03/235393-14\$15.00/0
}

associated neurite growth inhibitor (Spillmann et al., 1998; Chen et al., 2000; GrandPré et al., 2000; Prinjha et al., 2000).

The nogo gene gives rise to three major protein products, Nogo-A, $-\mathrm{B}$, and $-\mathrm{C}$, by both alternative splicing and alternative promoter usage (Chen et al., 2000; Oertle et al., 2003b). All Nogo isoforms share a common C-terminus of 188 amino acids, called reticulon-homology domain (RHD; Pfam PF02453) because of its similarity with the Reticulon (RTN) protein family (Roebroek et al., 1994, 1998; Moreira et al., 1999; Oertle et al., 2003c). Outside of this RTN domain, Nogo and the other three RTN genes have no obvious sequence similarities. Two long hydrophobic stretches (35 and 36 aa), which could serve as transmembrane (TM) domains and are probably responsible for the endoplasmic reticulum (ER) association of the proteins, are located in the RHD (van de Velde et al., 1994; Oertle et al., 2003a).

Myelin, oligodendrocytes, rat NI-250/NI-35 (for neurite outgrowth inhibitor of $\mathrm{M}_{\mathrm{r}} 250$ and $35 \mathrm{kDa}$ ) as well as purified bovine Nogo-A-ortholog bNI-220 were shown to be inhibitory for fibroblast spreading and neurite outgrowth and to induce growth cone collapse of rat dorsal root ganglion (DRG) and chick retinal ganglion cell (RGC) neurons (Caroni and Schwab, 1988; Bandtlow et al., 1993; Rubin et al., 1995; Loschinger et al., 1997; Spillmann et al., 1998). The identification of the regions of Nogo-A that exert these diverse inhibitory effects in vitro and their possible accessi- 
bility at the cell surface of oligodendrocytes would help us understand the mechanisms underlying the lack of regeneration in the $\mathrm{CNS}$ of higher vertebrates. Moreover, this information is crucial for the identification of Nogo-interacting molecules and for the development of optimal reagents for the neutralization of Nogo proteins. Potent neurite growth inhibitory activity was found in the Nogo-A-specific part of the molecule (Chen et al., 1999; Oertle et al., 2000; Prinjha et al., 2000). However, Nogo-A does not appear to be a conventional type I membrane protein: it does not possess an $\mathrm{N}$-terminal hydrophobic sequence that could serve as a signal peptide such as is common to proteins that are secreted or expressed at the cell surface.

GrandPré et al. (2000) presented evidence that the 66 amino acid residue region (termed Nogo-66) between the two hydrophobic stretches of the RTN domain induces growth cone collapse and is exposed on the surface of nogo-A-transfected cells. The cloning of a glycosyl phosphatidyl inositol (GPI)-anchored receptor (NgR) has been described recently that interacts with the Nogo-66 peptide (Fournier et al., 2001) as well as with the CNS myelin proteins OMgp (oligodendrocyte-myelin glycoprotein) and MAG (myelin-associated glycoprotein), both of which also have neurite growth inhibitory activity (Domeniconi et al., 2002; Liu et al., 2002; Wang et al., 2002a). The observation that Nogo-66 is inhibitory implies that all three Nogo isoforms should exert neurite growth inhibitory properties.

In the present study we provide evidence that three discrete regions of Nogo-A exhibit different inhibitory properties in vitro. Binding of Nogo-A-specific fragments to brain cortical membranes and the surface of responsive cells strongly argues for the existence of Nogo-A-specific receptor molecules. Antibody studies are suggestive for the expression of Nogo-A at the cell surface of cultured oligodendrocytes and of 3T3 fibroblasts and would imply that the N-terminal region of Nogo-A as well as the Nogo-66 region can face the extracellular space. A large intracellular pool of Nogo-A is associated with the endoplasmic reticulum (ER) and Golgi complex as revealed by double staining with marker proteins for these two organelles. Selective permeabilization studies suggest that a major part of the intracellular Nogo-A exhibits a second topology in which the N-terminus and NogoA-specific part of the molecule are exposed at the cytoplasmic side of membranes.

\section{Materials and Methods}

Rat Nogo-A deletion library. Deletion constructs have been made using internal restriction sites, by ExonucleaseIII/Mung Bean Nuclease treatment and by PCR with rat Nogo-A-specific primers on rat Nogo-A, Nogo-B, or Nogo- $C$ as templates (Chen et al., 2000): Nogo-A (aa 1-1163), Nogo-B (aa 1-172 + 976-1163), Nogo-C (Nogo-C N-terminal 11 aa + aa 976-1163), Nogo-66 (aa 1019-1083), rat glutathione $S$-transferase (GST)-Nogo-66 (aa 1026-1091), NiR-G (aa 1-979), NiR (1-172), NiR- $\Delta 1$ (aa 1-31), NiR- $\Delta 2$ (aa 59-172), NiR- $\Delta 3$ (aa $1-31+$ 59-172), EST (aa 762-1163), NiG (aa 174-979), NiG- $\Delta 1$ (aa 174-909), NiG- $\Delta 2$ (aa 174-865), NiG- $\Delta 3$ (aa 172-723), NiG- $\Delta 4$ (aa 172-646), NiG- $\Delta 5$ (aa 293-647), NiG- $\Delta 6$ (aa 763-975), NiG- $\Delta 7$ (aa $174-235+$ 294-979), NiG- $\Delta 8$ (aa 218-653), NiG- $\Delta 9$ (aa 172-259 + 646-974), NiG- $\Delta 10$ (aa 293-979), NiG- $\Delta 11$ (aa 209-268), NiG- $\Delta 12$ (aa 198-233), NiG- $\Delta 13$ (aa 174-216), NiG- $\Delta 14$ (aa 174-260), NiG- $\Delta 15$ (aa $174-190$ + 493-979), NiG- $\Delta 16$ (aa $174-190+621-979$ ), NiG- $\Delta 17$ (aa $174-190$ + 259-979), NiG- $\Delta 18$ (aa $174-190+263-979$ ), NiG- $\Delta 19$ (aa 763865 ), NiG- $\Delta 20$ (aa 544-725), NiG- $\Delta 21$ (aa $812-918$ ), NiG- $\Delta 22$ (aa $866-$ 975), NiG- $\Delta 23$ (aa 914-975), NiG- $\Delta 24$ (aa 544-685), NiG- $\Delta 25$ (aа 614-725), NiG- $\Delta 26$ (aa 544-613), NiG- $\Delta 27$ (aa $581-648$ ), NiG- $\Delta 28$ (aa 614-685), NiG- $\Delta 29$ (aa 648-725), NiG- $\Delta 30$ (aa 682-725), NiG- $\Delta 31$ (aa 544-580), NiG- $\Delta 32$ (aa 581-613), NiG- $\Delta 33$ (aa 614-648), NiG- $\Delta 34$ (aa 648-685), NiG- $\Delta 35$ (aa 260-556), NiG- $\Delta 36$ (aa 260-415). Human
GST-Nogo-66 (aa 1055-1120 of human Nogo-A) has been cloned by PCR on human Nogo-A as a template.

Deletion constructs were cloned into pET28 vector (Novagen), pGEX-6P (Amersham Biosciences) and pET26 vector (Novagen). Human GST-Nogo-66 corresponds to the GST-nogo protein published by GrandPré et al. (2000). Synthetic rat peptide 4 EELVQKYSNSALGHVNSTIKELRRL corresponds to the human peptide 4 (ibid.) with one mismatch. Synthetic Pro/Ser-rich peptide (PSSPPPSSPPPSSPPPS) as well as rat peptide 4 have been produced and HPLC-purified by Primm SA. P472 (NYESIKHEPENPPPYEEA) was synthesized and purified by Research Genetics.

Production of recombinant Nogo-A-deletion library. The bacterial Nogo-A-deletion library was expressed in Escherichia coli. Proteins were extracted by repeated sonication in sonication buffer $(20 \mathrm{~mm}$ Tris, $50 \mathrm{mM}$ $\mathrm{NaH}_{2} \mathrm{PO}_{4}, 100 \mathrm{~mm} \mathrm{NaCl}, \mathrm{pH} 8.0$ ) with $0.75 \mathrm{mg} / \mathrm{ml}$ Lysozyme, by solubilization with B-Per (Pierce), or with $8 \mathrm{M}$ urea. NiG expressed with pelBleader was obtained from the periplasmic space according to the Novagen protocol for periplasmic protein purification. Supernatants of pET28 constructs were purified using the $\mathrm{Co}^{2+}$-Talon Metal Affinity Resin (Clontech) in a batch procedure. Urea $(8 \mathrm{M})$ and B-Per solubilized lysates were brought to nondenaturing conditions by increasingly substituting the buffer with sonication buffer during the resin-batch procedure. Proteins were eluted with $250 \mathrm{~mm}$ imidazole in sonication buffer on a gravity column (Bio-Rad). NiG was further purified by gel filtration on Superdex 200 (Amersham Biosciences) HiLoad 16/60. Supernatants of pGEX-6P constructs were purified with G-Sepharose column in a batch procedure according to manufacturer's instructions (Amersham Biosciences). Cleavage of GST-Nogo-66 was performed by incubating solubilized GST-Nogo-66 with PreScission protease and subsequent HPLC purification.

Gel electroelution was performed by preparative SDS-PAGE of immobilized metal-affinity chromatography (IMAC)-purified recombinant Nogo and elution with Bio-Rad Electro-Eluter into 50 mм Tris, pH 7.4, $100 \mathrm{~mm} \mathrm{NaCl}, 0.2 \%$ (w/v) 3-[(3-cholamidopropyl)dimethylammonio]1-propanesulfonate (CHAPS) for $1 \mathrm{hr}$ at $250 \mathrm{~mA}$, followed by $30 \mathrm{sec}$ of reversed electrode polarities.

Protein concentrations of chromatography-purified proteins were determined using Pierce Coomassie Stain and BSA as standard protein. Protein concentrations of gel-eluted proteins were estimated on the basis of band intensity of silver-stained gels (Merril et al., 1981) with BSA as a standard.

Production of recombinant Nogo in Chinese hamster ovary cells. A 3119 bp fragment resulting from a partial HincII digest of rat Nogo-A cDNA, NiR-G, was cloned into pSecTag2 expression vectors (Invitrogen, Groningen, The Netherlands). Transfection of pNiR-G into Chinese hamster ovary $(\mathrm{CHO})$ cells resulted in intracellular, cytoplasmic expression of NiR-G. Stable NiR-G CHO cell lines were selected with $250 \mu \mathrm{g} / \mathrm{ml}$ Zeocin (Invitrogen). Recombinant NiR-G from cell lysate was purified over a $\mathrm{Ni}^{2+}$-NTA column (Qiagen AG, Basel, Switzerland).

Rat NiG- $\Delta 20$ and Nogo- 66 were cloned into pAPtag 5 vector by PCR. Transfection of pNiG- $\Delta 20$-AP into $\mathrm{CHO}$ cells resulted in NiG- $\Delta 20-\mathrm{AP}$ that was secreted into the culture supernatant. Stable pNiG- $\Delta 20-\mathrm{AP}$ and pNogo-66-AP cell lines were selected with $250 \mu \mathrm{g} / \mathrm{ml}$ Zeocin (Invitrogen). Both cell lines were adapted to serum-free medium (Invitrogen) conditions and grown in a cell-line chamber (Integra). Supernatants were concentrated 10-fold before use, and the concentration of fusion protein was assessed as described elsewhere (Flanagan and Leder, 1990).

Cloning of rat $\mathrm{NgR}$ and stable $\mathrm{NgR}$-expressing $\mathrm{CHO}$ cell line. Adult rat brain poly- $\mathrm{A}^{+}$-RNA was prepared using the Direct Quick Messenger RNA kit (Talent) according to manufacturer protocol. cDNA was prepared from $250 \mathrm{ng}$ of poly-A ${ }^{+}$-RNA with Moloney murine leukemia virus reverse transcriptase polymerase and poly-dT primers from Novagen. cDNA $(1 \mu \mathrm{g})$ was used as a template for a PCR of 35 cycles with 5'-GTTCGGATCCAAGATGAAGAGGGCGTCC-3' and 5' GTTCTCGAGTCAGCAGGGCCCAAGCACTG-3' as forward and reverse primers, respectively. The PCR product was subcloned into the BamHI-XhoI sites of pBluescriptII-KS and fully sequenced (Microsynth GmbH, Balgach, Switzerland).

$\mathrm{pIg} \kappa-\mathrm{V} 5-\mathrm{NgR}$ was derived by subcloning rat NgR lacking the signal 
peptide into BamHI-XhoI sites of pSecTag2A with primers $5^{\prime}$ GCTCGGATCCACCTGGTGCCTGTGTGTG-3' and 5'-GTTCTCGAGTCAGCAGGGCCCAAGCACTG-3' in frame with the Ig $\kappa$-leader peptide of the vector and $\mathrm{C}$ terminal to an introduced V5-tag (cloned by PCR from pYES2/NT with 5'-CACGAAGCTTGGGTAAGCCTATCCCT- $3^{\prime}$ and $5^{\prime}$-GTGGATCCGACGTAGAATCGAGACC-3' into Hin$d \mathrm{III}-\mathrm{BamHI}$ sites of pSecTag2A). A stable $\mathrm{pIg} \kappa-\mathrm{V} 5-\mathrm{NgR} \mathrm{CHO}$ cell line was selected with $250 \mu \mathrm{g} / \mathrm{ml}$ Zeocin (Invitrogen).

Radioactive labeling and binding experiments. IMAC-purified NiG$\Delta 20$ was iodinated by ANAWA Trading SA (Wangen, Switzerland) (2030 $\mathrm{Ci} / \mathrm{mmol}$ ) using Lactoperoxidase and purified by reverse-phase HPLC. Membranes from rat brain cortex were prepared as described (Olpe et al., 1990). Binding was performed for $1 \mathrm{hr}$ at room temperature essentially as described (Kaupmann et al., 1997) using $1.5 \mathrm{ml}$ tubes preincubated for 2 hr with $1 \%(\mathrm{w} / \mathrm{v})$ bovine serum albumin to reduce nonspecific binding. Membrane homogenates in HEPES buffer, pH 7.4 (125 mM NaCl, $5 \mathrm{~mm}$ $\mathrm{KCl}, 0.6 \mathrm{mM} \mathrm{MgCl}_{2}, 1.8 \mathrm{~mm} \mathrm{CaCl}_{2}, 20 \mathrm{~mm}$ HEPES, $6 \mathrm{~mm}$ dextrose), containing protease inhibitors (Rôche Diagnostics, Mannheim, Germany) were incubated with $1.3 \mathrm{~nm}$ iodinated NiG- $\Delta 20$ in the absence or presence of increasing concentrations of unlabeled NiG- $\Delta 20$.

Antibodies. Rat and bovine antisera (AS) 472 were produced against the synthetic peptide NYESIKHEPENPPPYEEA (bovine sequence) or the corresponding rat sequence SYDSIKLEPENPPPYEEA (aa 623-640) (Chen et al., 2000) (Research Genetics Huntsville, AL). AS 922 was raised against the peptide RIYKGVIQAIQKSDEGHPFRAYLESEVAISEELVQKYSNSALGHV (aa 1055-1099 of human Nogo-A) from the Nogo-66 region, and AS 294 was raised against the C-terminal Nogo-A peptide KDAMAKIQAKIPGLKRKAD (Research Genetics). AS Rosa and AS Bianca were produced by intradermal immunization of prokaryotically produced, IMAC-purified, and gel electroeluted NiR-a and NiR- $\Delta 3$. AS Florina and AS Laura were produced similarly by intradermal immunization of NiG. As controls, the corresponding preimmune sera or antisera preincubated with an excess of the corresponding immunogenic peptides were used.

For the monoclonal antibodies, mice ( $\mathrm{C} 3 \mathrm{H}$ and $\mathrm{C} 57 \mathrm{BI} 6 / \mathrm{J}$ strains) were immunized subcutaneously with the synthetic peptide SYDSIKLEPENPPPYEEA, corresponding to rat sequence aa 623-640 for monoclonal antibody $(\mathrm{mAb}) 11 \mathrm{C} 7$, whereas $\mathrm{mAbs} 11 \mathrm{~A} 8,7 \mathrm{~B} 12$, and $3 \mathrm{D} 11$ were produced against recombinant prokaryotically produced NiR-G. Spleen cells were fused with myeloma cells, and monoclonal lines were selected and subcloned. Supernatants of the obtained clones were screened on ELISA plates coated with the Nogo-A deletion library to localize their epitopes.

Rabbit anti-NgR antisera (AS $\alpha-\mathrm{NgR}$ ) were raised against three synthetic peptides of human NgR (EQLDLSDNAQLRSVDPA, EVPCSLPQRLAGRDLKR, and GPRRRPGCSRKNRTRS) and affinity purified by Research Genetics.

Western blot analysis. SDS-PAGE and Western blotting were performed as described previously (Kelleher et al., 1992; Huber et al., 2002); blocking was done with $3 \%$ (w/v) Top Block (Juro Supply, Lucerne, Switzerland). Antibodies were diluted as follows: AS 472 1:2000; AS Bianca 1:10,000; AS Florina: 1:20,000; affinity-purified AS $9221.5 \mu \mathrm{g} / \mathrm{ml}$; affinity-purified AS $2940.3 \mu \mathrm{g} / \mathrm{ml}$; affinity-purified AS $\alpha$-NgR 0.11 $\mu \mathrm{g} / \mathrm{ml} ; \alpha$-BiP $2 \mu \mathrm{g} / \mathrm{ml}$ (Stressgen); mAb $\alpha$ - $\beta$-tubulin (Boehringer Mannheim, Mannheim, Germany) 1:200; mAb 9E10 $\alpha$-myc (Invitrogen) 1:5000; monoclonal hybridoma culture supernatants 1:150. Secondary antibodies were HRP-conjugated goat anti-rabbit (Pierce; 1:20,000) and anti-mouse (1:50,000).

Cell surface biotinylation. Brain oligodendrocyte cultures (van der Haar et al., 1998) were incubated with 2 mg EZ-LINK-Sulfo-NHS-LCBiotin $(0.25 \mathrm{mg} / \mathrm{ml})$ (Pierce) per $75 \mathrm{~cm}^{2}$ flask for $30 \mathrm{~min}$ at $20^{\circ} \mathrm{C}$ followed by incubation with $8 \mathrm{ml}$ of $10 \mathrm{~mm}$ glycine in PBS with $\mathrm{Ca}^{2+} / \mathrm{Mg}^{2+}$ for 15 min to stop the biotinylation reaction and three washes with PBS. Cells were scraped, lysed in $1 \mathrm{ml}$ lysis buffer $\left[0.05 \mathrm{M} \mathrm{NaH}_{2} \mathrm{PO}_{4} \mathrm{pH} 8.0,0.15 \mathrm{M}\right.$ $\mathrm{NaCl}, 0.5 \%$ (w/v) CHAPS (Sigma), $2.5 \mathrm{~mm}$ iodacetamide, $1 \mathrm{~mm}$ phenylmethylsulfonyl fluoride, $0.1 \mu \mathrm{g} / \mathrm{ml}$ aprotinin, $1 \mu \mathrm{g} / \mathrm{ml} \mathrm{leupeptin,} 1 \mu \mathrm{g} / \mathrm{ml}$ pepstatin A] and precipitated three times with $100 \mu \mathrm{l}$ of Dynabeads M-280 streptavidin (Dynal).

Immunocytochemistry. Optic nerve oligodendrocytes were prepared as described (Schwab and Caroni, 1988). Cultures (3-5 d old) grown on poly-L-lysine-coated coverslips were washed twice with PBS, fixed in $4 \%$ (w/v) paraformaldehyde (PFA), 5\% (w/v) sucrose in PBS for $15 \mathrm{~min}$ at room temperature; cells were permeabilized with $0.1 \%(\mathrm{v} / \mathrm{v})$ Triton $\mathrm{X}-100$ (Tx-100) in PBS, and nonspecific binding was blocked with $10 \%$ $(\mathrm{v} / \mathrm{v})$ FCS. Cells were then incubated with affinity-purified AS 472 (1: $200)$ or AS 922 (1:100) hybridoma culture supernatants containing $\mathrm{mAb}$ 11A8, mAb 3D11, and mAb 11C7 (all 1:100), anti-MG160 (1:100), and anti-calnexin (1:1000) for confocal microscopy in PBS, 1\% FCS, $0.1 \%$ $(\mathrm{v} / \mathrm{v}) \mathrm{Tx}-100$. Selective permeabilization of the plasma membrane was performed as described by De Strooper et al. (1997) with modifications. The cultures were washed twice with $10 \mathrm{~mm}$ PIPES buffer, $\mathrm{pH}$ 6.8, containing $0.3 \mathrm{M}$ sucrose, $0.1 \mathrm{M} \mathrm{KCl}, 2.5 \mathrm{~mm} \mathrm{MgCl}_{2}$, and $1 \mathrm{~mm}$ EDTA (De Strooper et al., 1997), followed by incubation of $50 \mathrm{~min}$ at room temperature in PIPES buffer with $12.5 \mu \mathrm{g} / \mathrm{ml}$ digitonin, containing the primary antibodies. Cells were washed with PIPES buffer and fixed and further processed. Secondary antibodies were goat anti-mouse tetramethylrhodamine isothiocyanate (TRITC) and goat anti-rabbit fluoresceinisothiocyanate (FITC) (Jackson ImmunoResearch Laboratories). A mouse monoclonal antibody against the KDEL sequence ( $\alpha$-BiP, 1:100; StressGen Biotechnologies, Victoria, British Columbia, Canada) was used to confirm the selective permeabilization of only the plasma membrane.

For cell surface staining, 2-d-old rat optic nerve cultures were incubated with AS 472 (1:500), AS 922 (1:500), AS Bianca (1:500), or monoclonal antibodies (undiluted supernatant) in medium for $25 \mathrm{~min}$ at room temperature. For $\mathrm{CHO}$ /oligodendrocyte co-cultures, $6000 \mathrm{CHO}$ cells per well were added $24 \mathrm{hr}$ before staining procedures. Cultures were washed, fixed with $4 \%(\mathrm{w} / \mathrm{v})$ PFA and $5 \%(\mathrm{w} / \mathrm{v})$ sucrose and blocked with $0.1 \mathrm{M}$

A
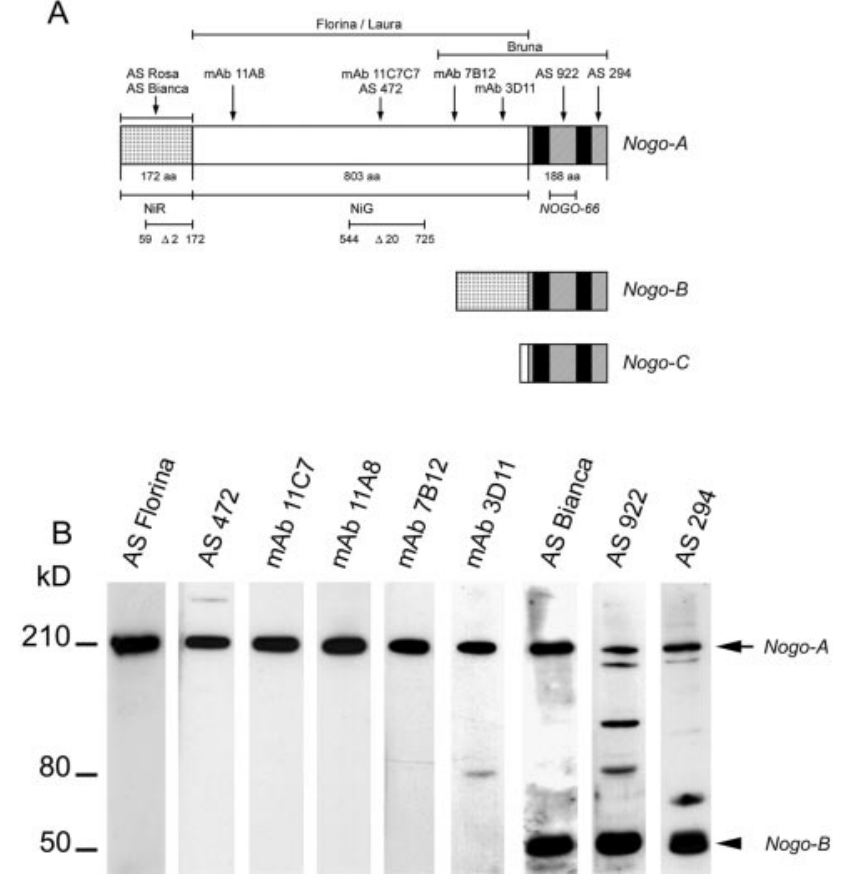

Figure 1. Nogo- $A,-B$, and $-C$ isoforms, main studied fragments, and antibodies raised against Nogo-A sequence and their specificity on oligodendrocytes. $A$, Several monoclonal antibodies and polyclonal rabbit antisera (AS) were raised against Nogo-A. AS 472 (Chen et al., 2000) and $\mathrm{mAb} 11 \mathrm{C} 7$ were raised against the same 18 aa peptide. The other three $\mathrm{mAbs}, 11 \mathrm{~A} 8$, 7B12, and 3D11, were raised against bacterially expressed NiR-G. AS Bianca was raised against bacterially produced NiR. AS 922 was raised against the Nogo-66 region between the two hydrophobic domains, and AS 294 was raised against the C terminus of Nogo. AS 922 and AS 294 recognize all Nogo isoforms. $B$, Western blot of lysates of cultured oligodendrocytes. The blot was incubated with different anti-Nogo-A antibodies. All antibodies recognize the $190 \mathrm{kDa}$ Nogo-A band (arrow) and mAb 3D11, AS 922, and AS 294 stain additional bands at 60 and 80 kDa, presumably Nogo-A breakdown products. AS Bianca, AS 294, and AS 922 also recognize Nogo-B at $\sim 55 \mathrm{kDa}$ (arrowhead). 
maleic acid with $2 \%(\mathrm{w} / \mathrm{v})$ blocking reagent (Rôche) for $1 \mathrm{hr}$. Secondary alkaline phosphatase-conjugated antibodies (Milan Analytica, Lausanne, Switzerland) were used at $1: 7500$ in $0.1 \mathrm{M}$ maleic acid with $1 \%(\mathrm{w} / \mathrm{v})$ blocking reagent $(1 \mathrm{hr})$. The cultures were washed twice with maleic acid buffer and once with alkaline phosphatase buffer $(0.1 \mathrm{M}$ Tris- $\mathrm{HCl}, \mathrm{pH}$ 9.5, $0.1 \mathrm{M} \mathrm{NaCl}, 5 \mathrm{~mm} \mathrm{MgCl}_{2}$ ), and the staining was developed for $3 \mathrm{hr}$ at room temperature with $0.175 \mathrm{mg} / \mathrm{ml}$ 5-bromo-4-chloro-3-indolylphosphate (Sigma) and $0.338 \mathrm{mg} / \mathrm{ml}$ nitroblue tetrazolium (Sigma) in alkaline phosphatase buffer. For surface MAG and intracellular Nogo-A, the staining was developed for $2 \mathrm{hr}$ instead of $3 \mathrm{hr}$.

The $\mathrm{pIg} \kappa-\mathrm{V} 5-\mathrm{NgR}$ CHO cells were washed, fixed for $15 \mathrm{~min}$ at room temperature, and blocked with $10 \%$ (v/v) FCS in PBS for 20 min at room temperature. mAb $\alpha$-V5 (Invitrogen R-960-25) was diluted 1:300 in 1\% (v/v) FCS in PBS for $1 \mathrm{hr}$ and washed, and secondary FITCconjugated anti-mouse antibodies (Jackson ImmunoResearch Laboratories) were used at 1:200 in PBS for $30 \mathrm{~min}$.

Flow cytometry. Flow cytometry and cell sorting were performed on a Cytomation MoFlo high-speed cell sorter (Fort Collins, CO). The flow cytometer was equipped with an argonion/UV Enterprise II laser tuned to $488 \mathrm{~nm}$ with $130 \mathrm{~mW}$ of power. Fluorescein (FITC) fluorescence was collected through a 530/40 nm bandpass filter. For analysis, 3T3 fibroblasts were detached with Cell Dissociation Buffer (Invitrogen) or $0.5 \%(\mathrm{w} / \mathrm{v})$ trypsin in PBS. The preformed complex used to detect binding of NiR-G to 3T3 fibroblasts was prepared as follows: NiR-G and anti-Myc antibody (9E10; Sigma) were incubated at a 1:1 molar ratio for 30 min at $4^{\circ} \mathrm{C}$. Next, FITC-conjugated $\mathrm{F}(\mathrm{ab})_{2}$ goat anti-mouse IgG was added and incubated for an additional $30 \mathrm{~min}$ at $4^{\circ} \mathrm{C}$. The resulting molar ratio of the trimeric complex was 1:1:0.5. The complex was added to $1 \times 10^{6} 3 \mathrm{~T} 3$ fibroblasts in a final volume of $100 \mu \mathrm{l}$, incubated for $2 \mathrm{hr}$ at $4^{\circ} \mathrm{C}$, washed, and analyzed by flow cytometry.

In vitro assays. $3 \mathrm{~T} 3$ fibroblast spreading assays were performed as described previously (Spillmann et al., 1998).

$\mathrm{CHO}$ spreading assays were performed essentially the same way as for 3T3 fibroblasts. Briefly, $\mathrm{CHO}$ cells were split 1:2. Twenty-four hours later they were trypsinized in PBS-EDTA for 30 sec, and $\sim 8000 \mathrm{CHO}$ cells were plated onto culture dishes precoated with $5,1,0.5$, and $0.2 \mu \mathrm{g}$ per well NiG or Nogo-66. After 30-45 min, the cells were fixed with $4 \%(\mathrm{w} / \mathrm{v})$ PFA, $5 \%(\mathrm{w} / \mathrm{v})$ sucrose and then analyzed.

PC12 neurite outgrowth assays were performed as described previously (Rubin et al., 1995).

Neurite outgrowth assays with P7 rat cerebellar granule cells were performed as described by Niederöst et al. (1999).

Retinal ganglion cell stripe assays were performed according to Vielmetter et al. (1990) with modifications (Schmalfeldt et al., 2000). Explants were evaluated after fixation with $4 \%(\mathrm{w} / \mathrm{v}) \mathrm{PFA}, 0.1 \%(\mathrm{v} / \mathrm{v})$ glutaraldehyde in PBS for $10 \mathrm{~min}$ at room temperature. For immunostainings, fixed explants were blocked for $1 \mathrm{hr}$ at room temperature with RNO-blocking solution [0.5\% (w/v) BSA, 0.3\% (w/v) TopBlock (Juro Supply), $0.1 \%$ (w/v) $\mathrm{NaN}_{3}$ in PBS], permeabilized for $10 \mathrm{~min}$
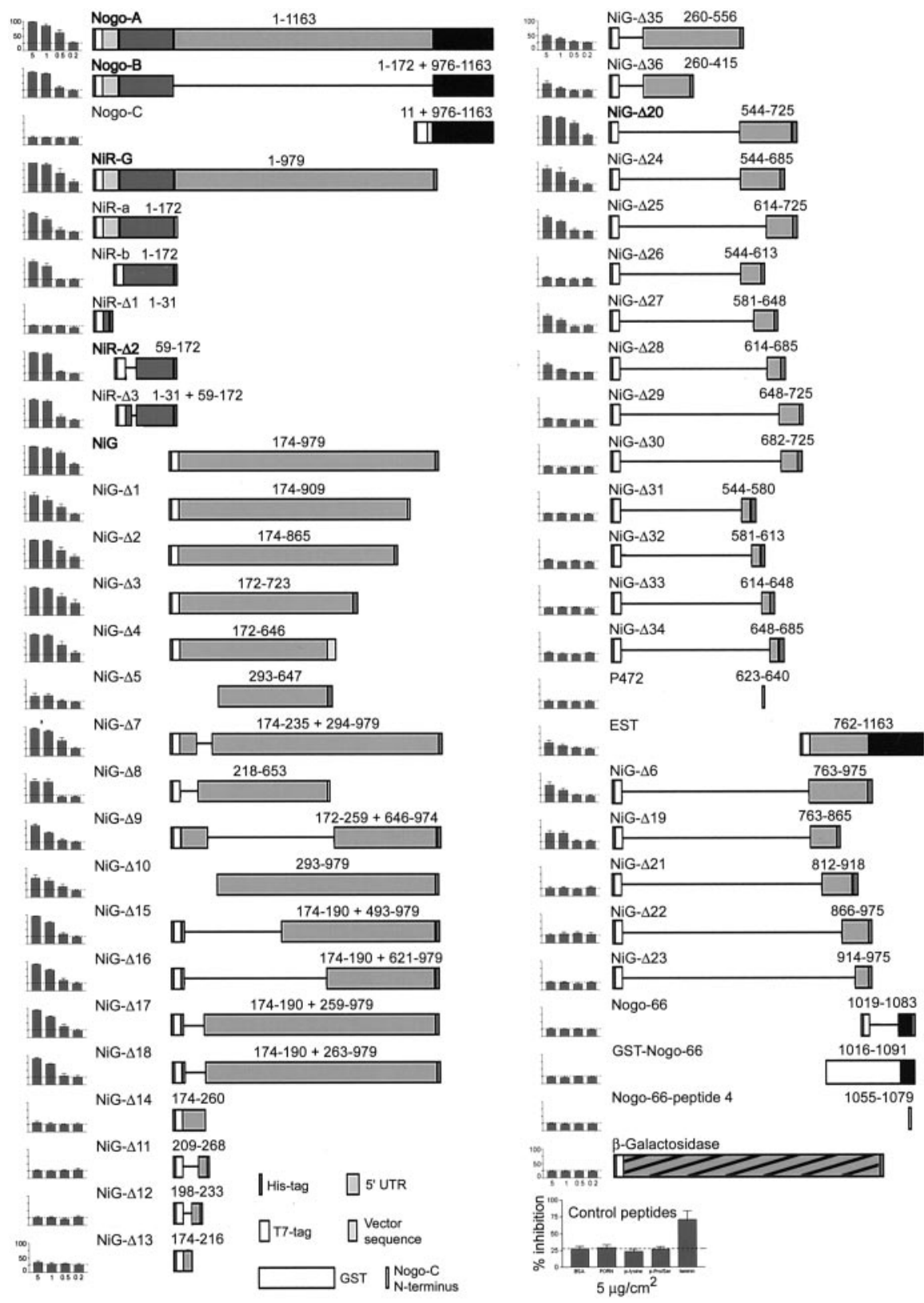

Figure 2. Analysis of the inhibitory properties of various Nogo fragments on $3 \mathrm{~T} 3$ fibroblast spreading. The main inhibitory activity resides in two regions of the Nogo-A protein. Nogo-A deletion products were tested for their relative inhibitory activity (percentage inhibition) on fibroblast spreading ( $5 \mu \mathrm{g} / 100 \mu \mathrm{l}, 1 \mu \mathrm{g} / 100 \mu \mathrm{l}, 0.5 \mu \mathrm{g} / 100 \mu \mathrm{l}$, and $0.2 \mu \mathrm{g} / 100 \mu \mathrm{l}$ of fragments coated per square centimeter). Mean of spreading on plastic is indicated by the dotted line. For each fragment at least three independent assays with proteins from at least two separate purifications were performed. The fragments that are most inhibitory for fibroblast spreading are highlighted. Control peptides ( $5 \mu \mathrm{g} / 100 \mu \mathrm{l}$ coated per square centimeter) did not exhibit inhibitory properties except for I-laminin. with $0.05 \%(\mathrm{v} / \mathrm{v}) \mathrm{Tx}-100$ in RNO-blocking solution, frozen for $1 \mathrm{~min}$ at $-20^{\circ} \mathrm{C}$, and incubated with primary antibodies (AS Bianca for NiR, AS Laura for Nogo-A, NiR-G, NiG, NiG- $\Delta 3$, and NiG- $\Delta 20$, and Novagen $\mathrm{mAb}$ anti-T7 for Nogo-C and $\beta$-Gal control protein). After washing with PBS, FITC- and TRITC-conjugated antibodies (Jackson ImmunoResearch Laboratories) were added (1:150) to the explants. The samples were coverslipped in 50\% (v/v) glycerol, $25 \mathrm{~mm} \mathrm{NaHCO}_{3}, 40 \mathrm{~mm} \mathrm{NaCl}$, $1 \%(\mathrm{w} / \mathrm{v}) \mathrm{p}$-phenylendiamine (Sigma).

Growth cone collapse assays on chick and rat DRG neurons were performed essentially as described previously (Bandtlow et al., 1993; Bandtlow and Löschinger, 1997; Fritsche et al., 1999). 


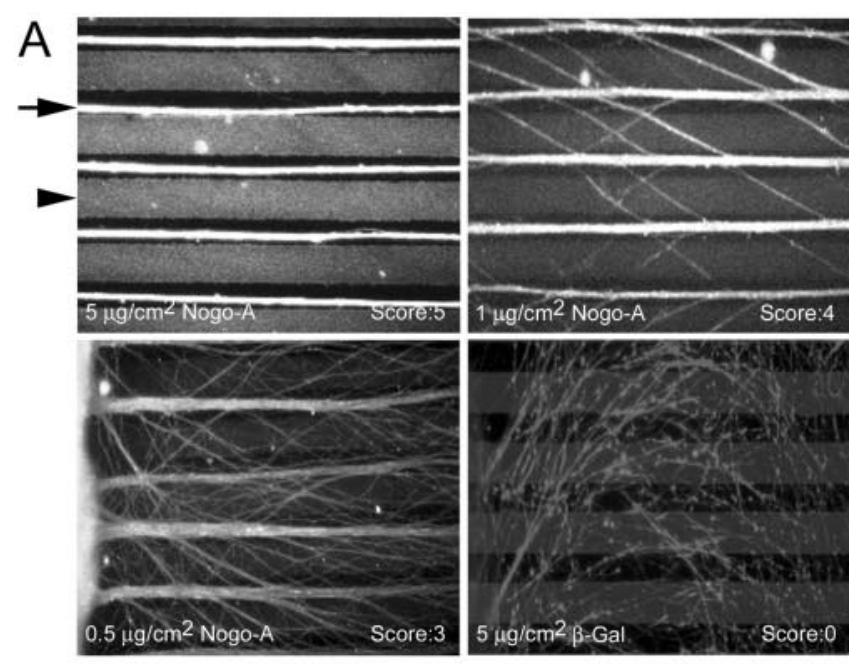

B
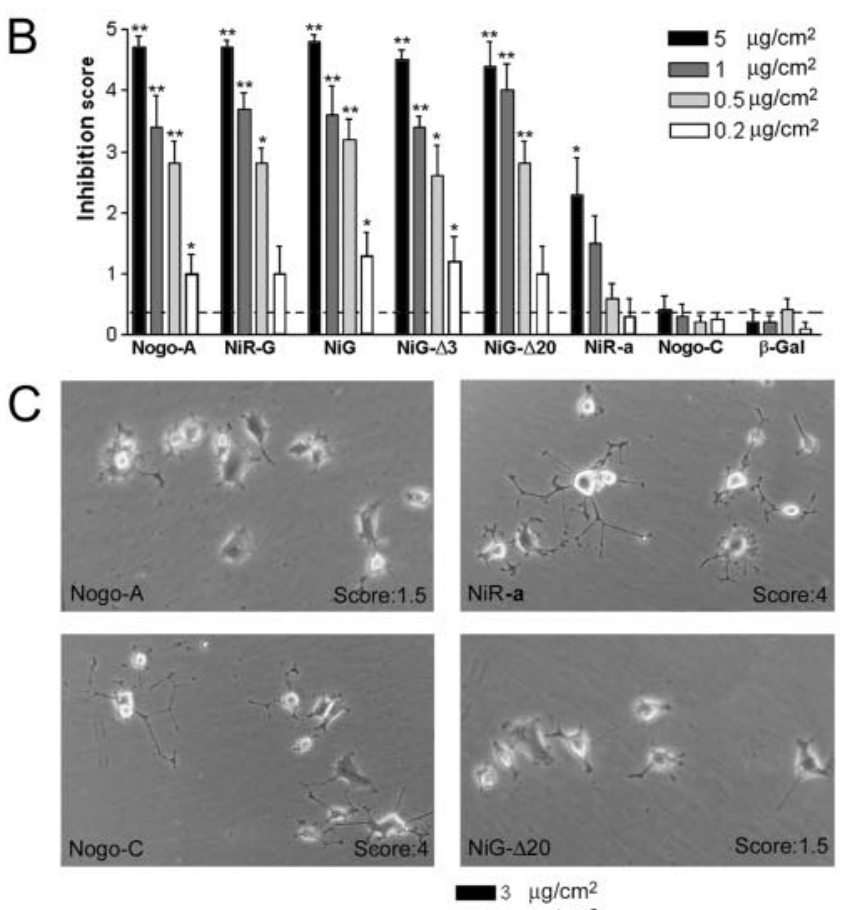

$-3 \mu \mathrm{g} / \mathrm{cm}^{2}$

$\mu \mathrm{gg} / \mathrm{cm}^{2}$

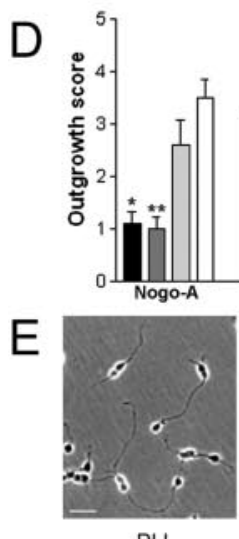

PLL

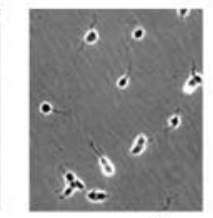

$0.5 \mu \mathrm{g} / \mathrm{cm}^{2}$ $\square 0.1 \mu \mathrm{g} / \mathrm{cm}^{2}$
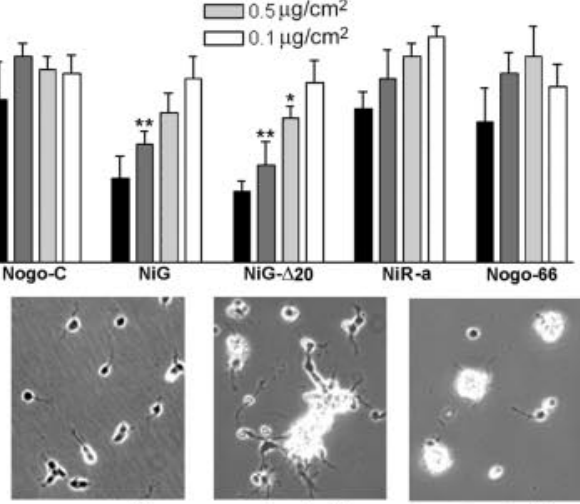

$1 \mu \mathrm{g} / \mathrm{cm}^{2}$

$2.5 \mu \mathrm{g} / \mathrm{cm}^{2}$

Figure 3. Analysis of the inhibitory activity of Nogo-A on neurite outgrowth. $A, B$, Nogo-A is an inhibitory substrate for E7-E9 RGC neurite outgrowth in a stripe assay. Stripes of Nogo/ laminin (arrowhead) versus laminin-only stripes (arrow) were compared. $A$, The axons (stained with anti-neurofilament $\mathrm{mAb}$ ) growing from chicken retina explants avoid the Nogo/laminin stripes (stained with AS Laura; arrowhead). This avoidance is concentration dependent and

\section{Results}

The three main isoforms of Nogo, the most important domains and active sites, and the epitopes of the antibodies and antisera used in this study are summarized in Figure 1.

\section{Two regions in the N-terminal part of Nogo-A are inhibitory} for spreading of $3 \mathrm{~T} 3$ fibroblasts

To identify the regions of Nogo-A responsible for the inhibition of 3T3 fibroblast spreading, a library of 50 Nogo deletion constructs was made, and recombinant proteins were expressed in bacteria (Fig. 2). The $\mathrm{Co}^{2+}$-affinity chromatography-purified Nogo fragments were coated on tissue-culture dishes. The purified material of some of the recombinant proteins contained lower molecular weight Nogo fragments (Chen et al., 1999), because the Nogo-A cDNA sequence contains internal ribosomal binding sites for E. coli and numerous rare codons (our unpublished observations). The purity of fragments was estimated on the basis of silver-stained SDS-PAGE (see Fig. 6D). The comparison between the different deletion constructs is therefore semiquantitative.

The apparent $\mathrm{EC}_{50}$ for inhibition of 3T3 fibroblast spreading was $\sim 400-500 \mathrm{ng} / 100 \mu \mathrm{l} \mathrm{Nogo-A}$ coated overnight per $\mathrm{cm}^{2}$ of culture dish $\left(\sim 4 \mathrm{pmol} / \mathrm{cm}^{2}\right)$. Treatment of Nogo-A or its fragments with $8 \mathrm{M}$ urea resulted in a strong reduction of inhibitory activity, indicating that conformation is important.

The analysis of Nogo fragments in the fibroblast spreading assay revealed that at least two stretches of the Nogo-A protein mediate inhibition of the spreading of freshly plated fibroblasts, namely aa 59-172 (NiR- $\Delta 2$ ) and aa $544-725$ (NiG- $\Delta 20)$ (Figs. 2, 3 ). All of the fragments derived from the Nogo-A-specific region (NiG) displaying inhibitory activity (e.g., NiG- $\Delta 4$ and NiG- $\Delta 8$ ) partially overlap with aa $544-725(\mathrm{NiG}-\Delta 20)$. Minor inhibitory activity at high protein concentration was seen for the $\mathrm{C}$-terminal part of the Nogo-A-specific region (aa 763-865; NiG- 119 ). At high concentrations, the anti-spreading activity of the Nogo fragments became anti-adhesive. These two effects could be overcome eventually by the cells after longer incubation times, indicating that they were not caused by toxic effects (data not shown). Nogo-C, Nogo-66, and Nogo-66 Peptide 4 [shown to be the inhibitory region of Nogo-66 by GrandPré et al. (2000)] were not inhibitory for fibroblast spreading (Fig. 2).

We found no correlation between the isoelectric point of the protein fragments and their inhibitory character. The high occurrence of proline and serine in the N-terminus of Nogo-A is also

accompanied by strong axonal fasciculation. Control $\beta$-galactosidase/laminin stripes (stained with $\alpha-\mathrm{T7} \mathrm{mAb}$ ) are permissive substrates for RGC axons. $B$, Inhibition score for RGC outgrowth on different Nogo fragments. Cultures were evaluated by giving a score of 5 for striped neurite outgrowth with no fibers crossing the Nogo containing stripes, 4-2 for striped neurite outgrowth with increasing numbers of crossing fibers, 1 for random outgrowth with tendency to grow in the direction of the stripes, and 0 for complete random neurite outgrowth. The dotted line indicates the mean of all $\beta$-galactosidase control experiments. Values are represented as mean $\pm S E$. The groups have been compared with the scores for Nogo-C at the same coated protein concentration $\left({ }^{*} p<0.05\right.$; ${ }^{* *} p<0.01$; Mann-Whitney $U$ test). C, Examples of $\mathrm{PC} 12$ neurite outgrowth on different substrates. On Nogo-A and its fragment NiG- $\Delta 20$, the number of neurites is reduced and they are shorter compared with cells grown on Nogo-C and NiR. D, Quantification of outgrowth of $\mathrm{PC} 12$ neurites grown on different Nogo substrates (scores from $0=$ no outgrowth to $5=$ long, branched neurites). Values are represented as mean $\pm \mathrm{SE}$. The groups have been compared with the scores for Nogo-C at the same coated protein concentration $\left({ }^{*} p<0.05 ;{ }^{* *} p<0.01\right.$; Mann-Whitney $U$ test). E, Primary rat cerebellar granule cells were plated on increasing amounts of coated NiG. The inhibition of neurite outgrowth and cell adhesion by NiG is dose dependent. 
not responsible for the observed effect because a poly-Pro/Ser peptide is not inhibitory (Fig. 2, Control peptides).

These data show that the anti-spreading activity of Nogo-A on 3T3 fibroblasts resides in two defined stretches located at the $\mathrm{N}$ terminus (aa 59-172) and within the Nogo-A-specific part (aa $544-725$; NiG- $\Delta 20)$ of the protein. Nonspecific physicochemical properties (acidity of the fragments, structural effects attributable to proline and serine residues) are not responsible for this effect. The C-terminal RTN-homology domain including Nogo-66 is not involved in the inhibition of fibroblast spreading.

\section{Several regions of Nogo-A are inhibitory for neurite outgrowth}

To determine whether the fragments of Nogo-A that were nonpermissive for cell spreading are also inhibitory for neurite outgrowth, we tested a series of bacterially produced Nogo-A fragments as well as eukaryotically produced Nogo-fragmentalkaline phosphatase (Nogo-AP) fusion proteins in different neuronal assays.

In a substrate stripe assay (Vielmetter et al., 1990), we tested whether Nogo stripes are inhibitory for the growing embryonic chicken [embryonic day (E) 7-9] RGC axons. Neurites avoided laminin/Nogo-A-coated stripes, growing on the laminin-only stripes (Fig. 3A), whereas stripes coated with laminin/ $\beta$ galactosidase were not circumvented. Full-length Nogo-A was strongly nonpermissive for RGC neurites, whereas the N-terminal part of Nogo-A/-B (aa 1-172) had only marginal effects. Nogo-C activity was indistinguishable from the control protein $\beta$-galactosidase (Fig. $2 A, B$ ). The Nogo-A-specific region NiG- $\Delta 20$ (aa $544-725$ ) appears to contain the main inhibitory region for these neurites (Fig. $3 B$ ). The growth cones were also seen to stop when entering $\mathrm{NiG}-\Delta 20$-coated "dead-end" lanes (data not shown). These nonpermissive effects were concentration dependent: increasing numbers of crossing fibers were observed at lower concentrations of Nogo-A or its active fragments (Fig. $3 A, B$ ). No obvious difference was detected between nasal and temporal RGC neurites concerning their responsiveness to Nogo-A regions.

A laminin-independent, NGF-responsive clone of PC12 cells (Rubin et al., 1995) was primed with $50 \mathrm{ng} / \mathrm{ml} \mathrm{NGF}$ for $24 \mathrm{hr}$ and then plated onto dishes coated with bacterially produced Nogo fragments at $0.1-3 \mu \mathrm{g} / \mathrm{cm}^{2}$. Neurite outgrowth was scored $1 \mathrm{~d}$ later. The Nogo-A-specific region (NiG) and its aa 544-725 fragment $(\mathrm{NiG}-\Delta 20)$ strongly inhibited PC12 neurite outgrowth (Fig. 3C,D). In contrast, the N-terminal fragment (aa 1-172) had only minor activity, detectable only at high protein concentration. Nogo-C and Nogo-66 were inactive.

Substrate-coated NiG (aa 174-979) also acted as a strong neurite growth inhibitor of primary mammalian neurons: neurite outgrowth of postnatal day (P) 7 rat cerebellar granule cells was prevented in a dose-dependent manner, and cells aggregated at higher Nogo substrate concentrations (Fig. 3E).

We further tested the growth cone collapsing activities of the various Nogo constructs. Murine GST-Nogo-66, human GSTNogo-66, and HPLC-purified Nogo-66 lacking the GST tag induced growth cone collapse of E13-E15 chicken DRG explants as described previously (GrandPré et al., 2000; Fournier et al., 2001). The growth cone collapsing activities of these proteins were relatively low $(\sim 50 \%$ collapsed at $\sim 1 \mu \mathrm{M})$ and varied between preparations, probably because of the poor solubility of these recombinant proteins. Nogo-66 peptide 4 was inactive. In contrast, soluble dimeric Nogo-66-AP was collapse-inducing in a
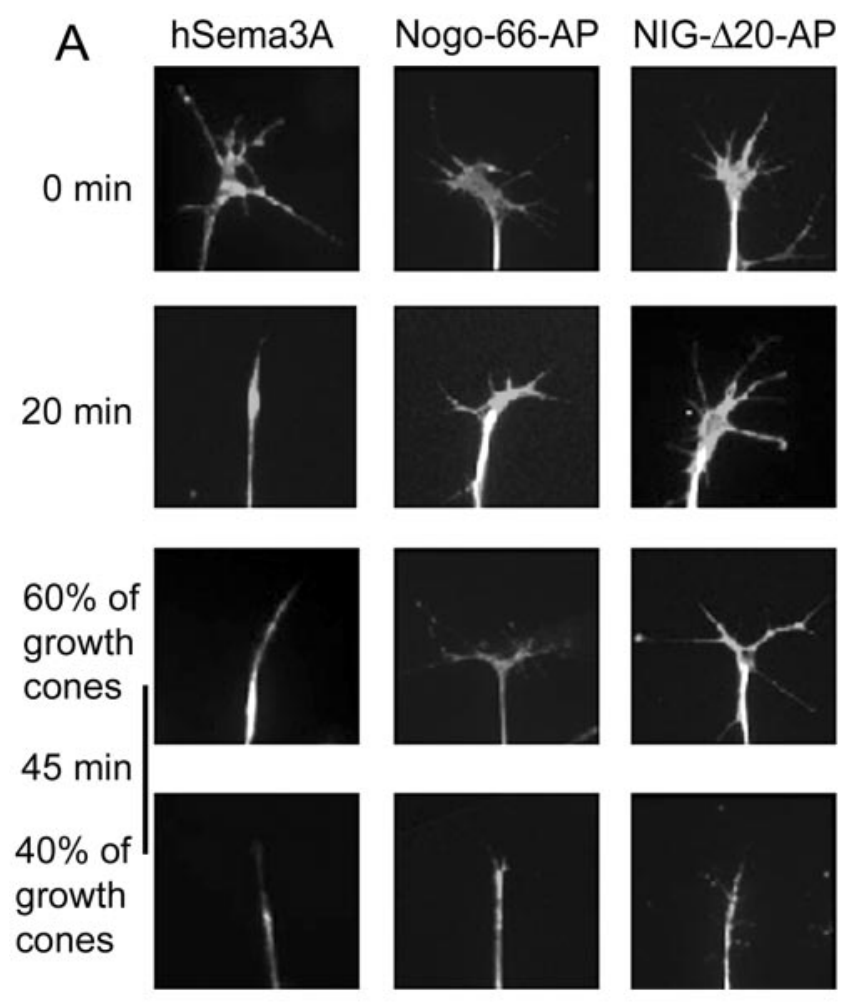

B

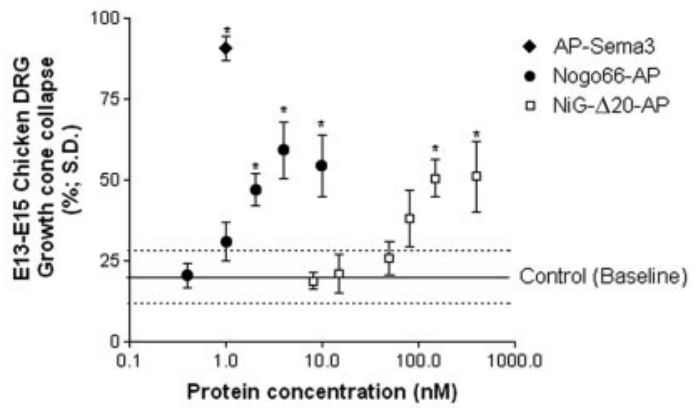

Figure 4. Analysis of the collapsing activity of different Nogo-A fragments on DRG growth cones. $A$, Time course of the growth cone collapse of dissociated rat P6 DRG neurons induced by preclustered NiG- $\Delta 20-A P$, Nogo-66-AP, or Sema3A. After the indicated time periods, the cultures were fixed and doubly labeled by anti-tubulin antibody and tetramethylrhodamine $B$ isothiocyanate-phalloidin. $B$, Dose-dependent growth cone collapse of chicken E13-E15 DRG explants treated with preclustered NiG- $\Delta 20-A P$, Nogo-66-AP, and AP-Sema3A. All three proteins induce growth cone collapse, but Nogo-66-AP is more potent than NiG- $\Delta 20-A P$. Both Nogo-AP fragments have a much weaker collapse-inducing activity than AP-Sema3A.

range similar to what has been described previously with an apparent $\mathrm{EC}_{50}$ of $\sim 2 \mathrm{~nm}$ (Fig. 4 B) (GrandPré et al., 2000). Growth cone collapse could also be elicited by the Nogo-A-specific, soluble, and dimeric fragment aa 544-725 (NiG- $\Delta 20$-AP), with an apparent $\mathrm{EC}_{50}$ of 200-400 nM (Fig. $4 B$ ). Bacterially expressed recombinant monomeric $\mathrm{NiG}$ (aa 174-979) or NiG- $\Delta 20$ (aa 544-725) had no collapse-inducing activities, nor had NiR-G (aa 1-979). Time-lapse studies on dissociated rat P6 DRG neurons revealed that growth cone collapse induced by Nogo-66-AP and $\mathrm{NiG}-\Delta 20$-AP occurred with a slower time course than collapse elicited by hSema3A (Fig. $4 A$ ). In addition, although AP-Sema3A induced collapse of virtually all growth cones at low nanomolar concentration, both Nogo-66-AP and NiG- $\Delta 20$-AP did not lead to collapse of $>60 \%$ of the rat or chicken growth cones (Fig. $4 A, B)$. 


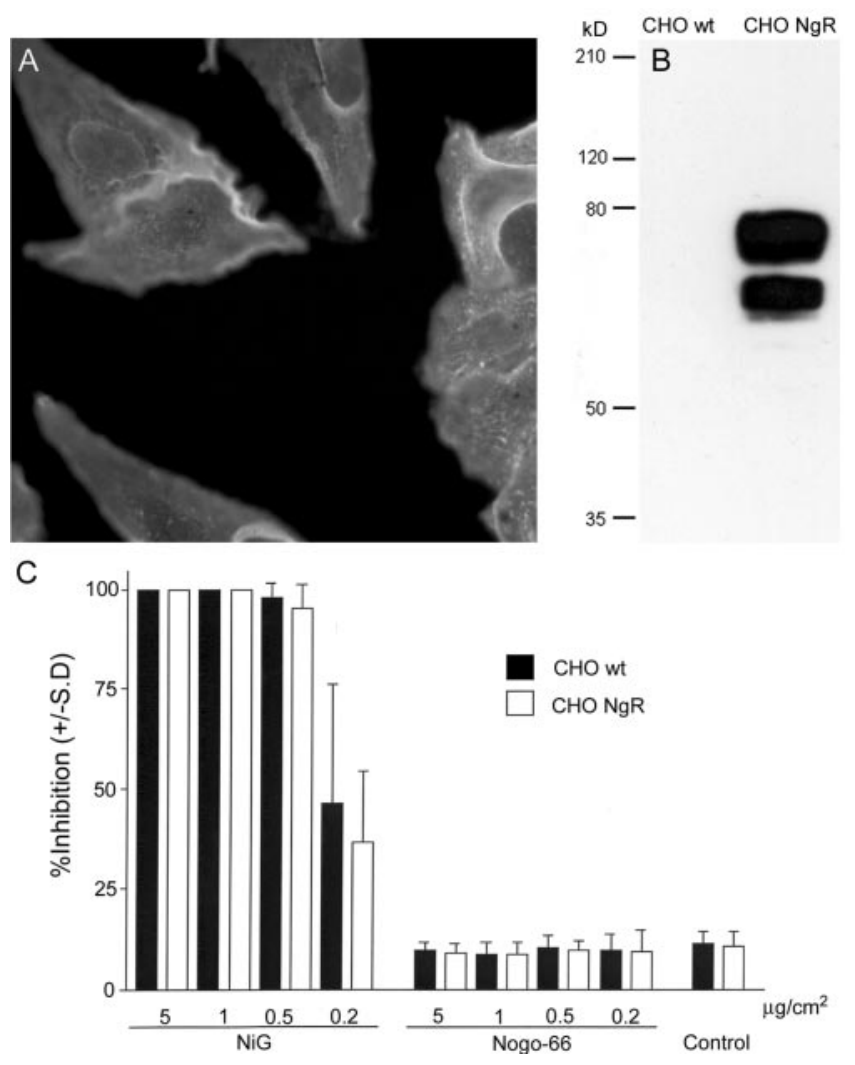

Figure 5. Activity of $\mathrm{NgR}$-expressing $\mathrm{CHO}$ cells versus wild-type cells on Nogo fragments. $A$, An $\mathrm{mAb}$ against the $\mathrm{V} 5$-epitope stains the surface of a $\mathrm{CHO}$ cell line stably transfected with rat $\mathrm{NgR}$. B, On Western blot, $\mathrm{no} \mathrm{NgR}$ protein is detectable in lysates of wild-type $\mathrm{CHO}$ cells, whereas high amounts of $\mathrm{NgR}$ are detectable in lysates of the $\mathrm{CH} 0-\mathrm{NgR}$ cell line. C, Both wild-type and $\mathrm{NgR}$-transfected $\mathrm{CHO}$ cells are strongly inhibited in spreading by the Nogo-A-specific region $\mathrm{NiG}$, whereas they are unresponsive to Nogo-66.

\section{The Nogo-66 receptor NgR is not required for inhibition of} cell spreading

We isolated a cDNA encoding the rat NgR protein (GenBank accession number AF462390) and generated antisera against specific peptides of the protein. To study the role of $\mathrm{NgR}$ for inhibition of cell spreading, we generated a $\mathrm{CHO}$ cell line stably expressing rat $\mathrm{NgR}$ at high levels on its cell surface (Fig. $5 A, B$ ). Wild-type $\mathrm{CHO}$ cells (CHO-wt) do not express detectable amounts of NgR as determined by RT-PCR (40 cycles; data not shown) and Western blotting (Fig. 5B). Spreading of both $\mathrm{CHO}-$ wt and $\mathrm{CHO}-\mathrm{NgR}$ was dose-dependently inhibited by Nogo-A aa 174-979 (NiG). Independent of NgR expression, neither cell line responded to coated Nogo-66 (Fig. 5C).

These results show that the inhibition of fibroblast-like cells by the Nogo-A-specific active region can occur in the absence of $\mathrm{NgR}$ and that the presence of NgR does not change the responsiveness of the cells to Nogo-66 or Nogo-A.

\section{Presence of binding site(s) for active Nogo-A-specific fragments on $3 \mathrm{~T} 3$ fibroblasts and rat brain cortical membranes}

Because the Nogo-A fragments aa 1-172 and aa 544-725 $(\mathrm{NiR}-\Delta 2$ and NiG- $\Delta 20)$ were inhibitory for cell spreading and neurite outgrowth despite the absence of Nogo-66 and independently of NgR, the presence of a separate, Nogo-A-specific receptor has to be postulated. We therefore performed binding studies of multimerized, myc-tagged, and IMAC-purified Nogo-A aa
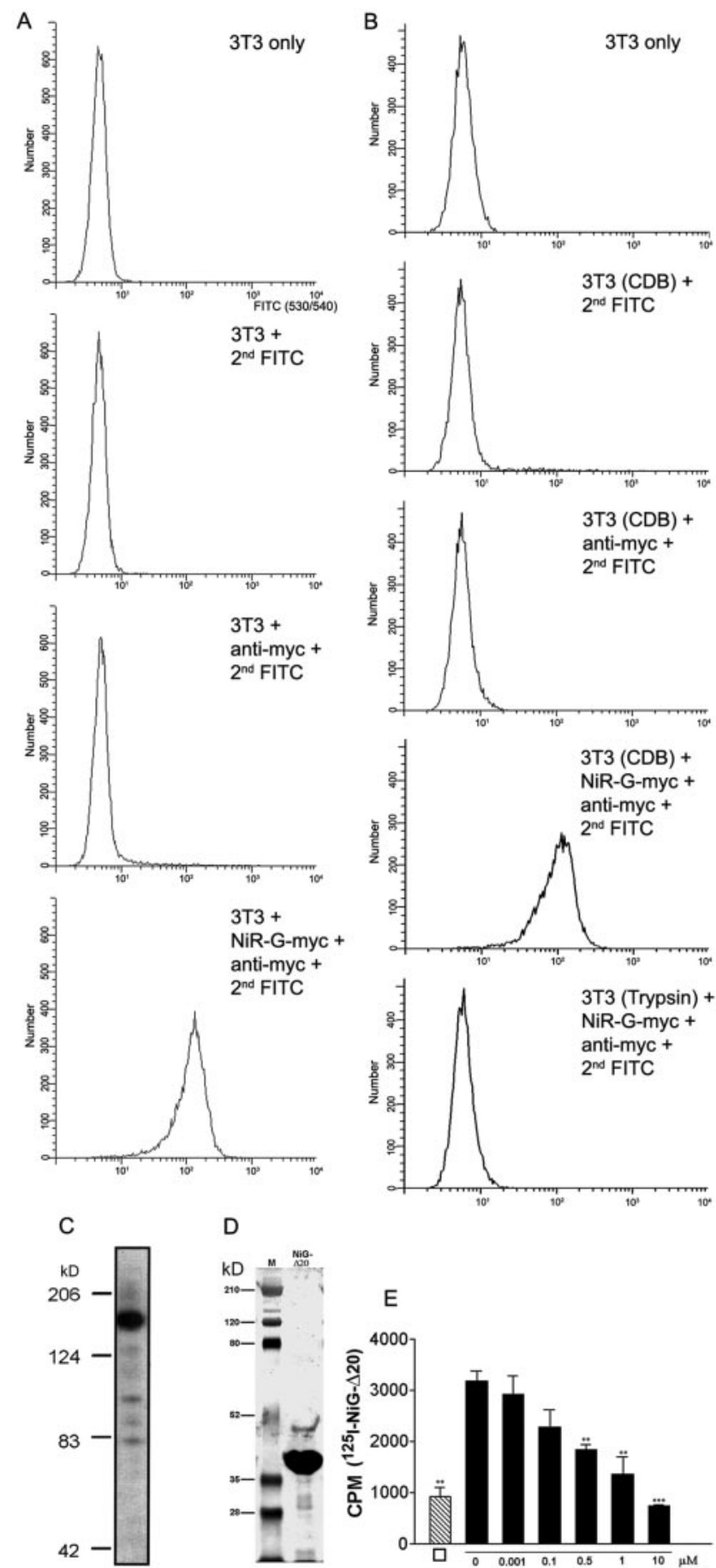

Figure 6. Binding of amino terminal Nogo fragments to 3 T3 cells and cortical membranes. $A_{\text {, }}$ Binding of NiR-G (aa 1-979) to 3T3 cells. 3T3 fibroblasts were incubated with a preformed complex consisting of $\alpha$-myc antibody (9E10), FITC-conjugated F(ab) ${ }_{2}$ goat $\alpha$-mouse lgG fragments, and myc-tagged amino-terminal fragment of Nogo-A (NiR-G). Binding of the complex to $3 T 3$ fibroblasts was analyzed by flow cytometry. Unstained $3 T 3$ fibroblasts were used as negative control. Further negative controls include $3 \mathrm{~T} 3$ cells incubated with a complex consisting of the $\alpha$-myc antibody and the FITC-conjugated $\alpha$-mouse Ab or with the FITC-conjugated $\alpha$-mouse Ab alone. B, Binding of NiR-G to $3 \mathrm{~T} 3$ cells is protease sensitive: trypsinization of $3 \mathrm{~T} 3$ fibroblasts before incubation with Nogo completely abolishes Nogo-binding to their surface. $C$, Western blot of purified, myc-epitope-tagged NiR-G. D, Silver-stained gel of IMAC-purified $\mathrm{NiG}-\Delta 20 . \mathrm{M}$, Molecular weight standard. E, Binding of $1.3 \mathrm{~nm}\left[{ }^{125} \mathrm{I}\right]-\mathrm{NiG}-\Delta 20$ to rat brain cortical membranes and competition by increasing concentration of unlabeled NiG- $\Delta 20$. $\square$ indicates the values obtained after incubation of $1.3 \mathrm{~nm}\left[{ }^{125}\right]$ ]-NiG- $\Delta 20$ in the absence of cortical membranes, i.e., nonspecific binding to the tubes. Values are represented as mean $\pm \mathrm{SE}$ $\left({ }^{* *} p<0.01 ;{ }^{* * *} p<0.001\right.$; Student's $t$ test for competition; $\left.n=3\right)$. 
1-979 (Fig. 6C) to living 3T3 fibroblasts. The cells were labeled in suspension at $4^{\circ} \mathrm{C}$ and subsequently analyzed by flow cytometry. Anti-myc monoclonal antibodycomplexed myc-tagged Nogo-A fragment (NiR-G) bound efficiently to $3 \mathrm{~T} 3$ cells as seen by a shift in fluorescence of $>90 \%$ of the 3T3 cells (Fig. 6A). In contrast, 3T3 cells were not labeled after incubation with the primary mouse anti-myc mAb complexed with an FITC-conjugated secondary $\mathrm{F}(\mathrm{ab})_{2}$ goat anti-mouse IgG in the absence of Nogo-A or with the secondary $\mathrm{Ab}$ alone. The binding of the amino terminal Nogo-A fragment to the surface of fibroblasts is protease sensitive, because 3T3 cells that were dissociated with trypsin before Nogo-A incubation do not bind Nogo-A (Fig. 6B).

To test binding of Nogo-A aa 544-725 (NiG- $\Delta 20)$ to rat cortical membranes, we used [ $\left.{ }^{125} \mathrm{I}\right]$-labeled NiG- $\Delta 20$ in a radioligand binding assay (Fig. 6D). [ $\left.{ }^{125} \mathrm{I}\right]$ labeled Nogo fragment bound to these brain plasma membranes. The specificity of binding was shown by a concentrationdependent competition of $\left[{ }^{125} \mathrm{I}\right]-\mathrm{NiG}$ $\Delta 20$ binding at a concentration of $1.3 \mathrm{nM}$ by increasing amounts of unlabeled NogoA aa $544-725$ (Fig. 6E).

These results show that defined, bioactive fragments of Nogo-A can bind to the surface of $3 \mathrm{~T} 3$ cells and rat cortical membranes, demonstrating the presence of membrane-bound, Nogo-A-specific binding sites or receptor(s) different from the Nogo-66 receptor NgR.
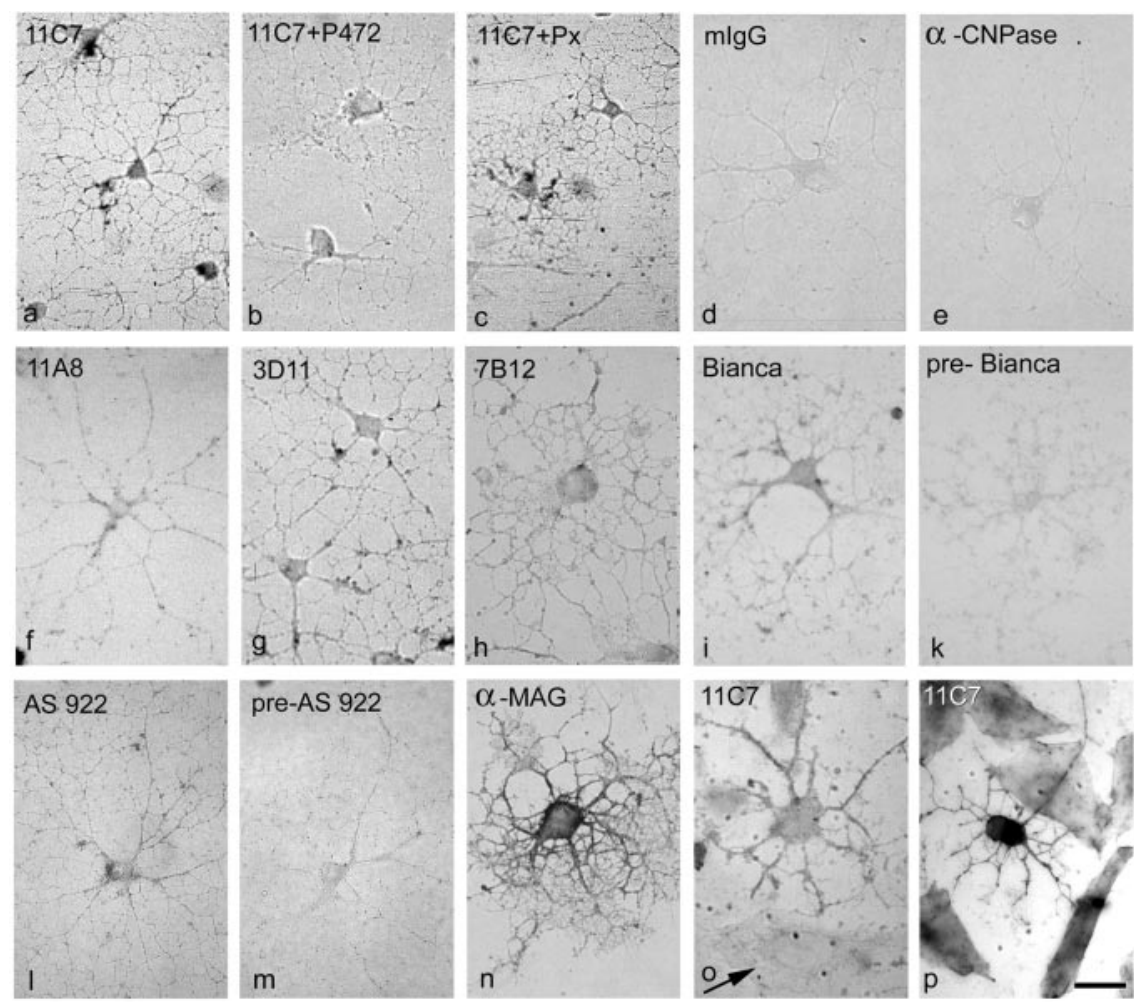

Figure 7. Nogo-A is present at the cell surface of cultured oligodendrocytes. Live, unpermeabilized oligodendrocytes ( $3 \mathrm{~d}$ in culture) were incubated with anti-Nogo-A antibodies, fixed, and visualized with secondary antibodies conjugated with alkaline phosphatase. All antibodies against the N-terminus of Nogo-A stain the cell surface of oligodendrocytes (mAb 11C7, mAb 11A8, mAb 3D11, mAb 7B12, AS Bianca), although more weakly than an antibody against the surface glycoprotein MAG (shorter development; see Materials and Methods). The control mouse lgG ( $d$ ) and an antibody against the intracellular oligodendrocyte protein CNPase (e) do not stain oligodendrocytes. Preincubation of 11C7 with the immunogen, peptide P472, reduced the staining to background levels $(b)$, whereas preincubation with an unspecific peptide (Px) did not result in a reduction in staining intensity $(c)$. Furthermore, AS 922 against the C-terminal Nogo-66-region stains the cell surface of living oligodendrocytes (I), whereas the corresponding preimmune serum (pre-922) gives only background staining $(m)$. Staining of co-cultures of oligodendrocytes with CHO cells expressing rat Nogo-A with mAb 11 C7 shows that although intact oligodendrocytes are stained, Nogo-A produced by $\mathrm{CHO}$ cells (arrow) is not detectable at the cell surface (o). Both cell types are stained with $11 C 7$ after permeabilization ( $p$ ). Scale bar, $25 \mu \mathrm{m}$.

\section{Antibodies against Nogo-A}

Antisera and monoclonal antibodies were raised against Nogo-A peptides or recombinant protein fragments (Fig. 1). The monoclonal antibody $11 \mathrm{C} 7$ was raised against Nogo-A aa 623-640, i.e., the same Nogo-A specific peptide as the rabbit AS 472 (Chen et al., 2000). Three other mAbs raised against Nogo-A aa 1-979 (NiR-G) reacted with different epitopes as determined by ELISA on the Nogo protein fragment library: 11A8 recognizes the most $\mathrm{N}$-terminal part of the Nogo-A-specific region ( aa 209-233), and 7B12 ( aa 763-820) and 3D11 ( aa 910-920) recognize the C-terminal part of the Nogo-A-specific region of the molecule. Two antisera (AS Bianca and AS Rosa) recognize the N-terminal region aa 1-172 (NiR), common to both Nogo-A and Nogo-B. Finally, antisera were raised against the Nogo-66 region (AS 922) and the $\mathrm{C}$ terminus of Nogo including the ER retention signal (AS 294), respectively.

Antibodies against all epitopes identified the $190 \mathrm{kDa}$ Nogo-A band on a Western blot of oligodendrocyte cell culture homogenate (Fig. 1 B). AS Bianca, AS 922, and AS 294 also recognize the $55 \mathrm{kDa}$ band of Nogo-B. mAb 3D11 and AS 922 recognized an additional band at $\sim 80 \mathrm{kDa}$, which could be a breakdown product of Nogo-A. At longer exposure times, AS 922 and AS 294 both stained additional bands even after affinity purification.

\section{Domains of Nogo-A present at the cell surface of cultured oligodendrocytes}

Cultures of unpermeabilized living oligodendrocytes were incubated with different anti-Nogo-A antibodies. The Nogo-Aspecific mAbs 11C7, 11A8, 7B12, and 3D11 (Figs. 1, 7a,f,g,h) as well as AS 472 (data not shown) stained the surface of the differentiated oligodendrocyte cell bodies and their process network. Compared with stainings for GalC or sulfatide (data not shown) or an $\mathrm{mAb}$ against the oligodendrocyte surface protein MAG (Fig. 7n), the Nogo staining was relatively weak. The specificity of the cell surface staining is suggested by the following results. (1) The control mouse IgG and the antibodies against the intracellular protein CNPase did not stain intact living cells (Fig. 7d,e). (2) Preincubation of mAb 11C7 (or AS 472; data not shown) with the corresponding immunogenic peptide $\mathrm{P} 472$ reduced staining to background levels (Fig. 7b). Preincubation of mAb 11C7 or AS 472 with an unspecific peptide $(\mathrm{Px})$ before their addition to the cells did not reduce the staining (Fig. 7c). (3) Co-cultures of oligodendrocytes with transfected Nogo-A-expressing $\mathrm{CHO}$ cells were stained with mAb 11C7. Although intracellular Nogo-A was detectable in both cell types after permeabilization (Fig. 7p), surface Nogo-A could be detected only on oligodendrocytes but not on the transfected $\mathrm{CHO}$ cells (Fig. 7o). This observation suggests that transport of Nogo-A to the cell surface could be cell-type 


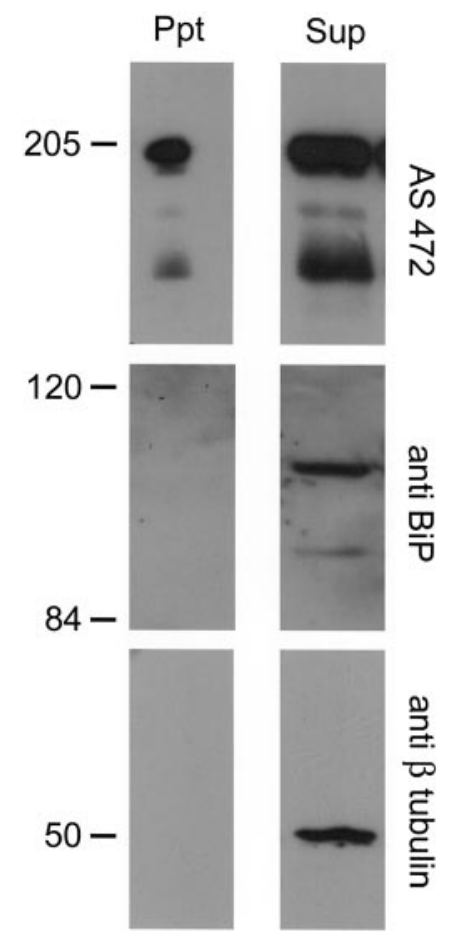

Figure 8. Precipitation of Nogo-A from cell-surface biotinylated oligodendrocytes. Living cultures of oligodendrocytes were incubated with a cell-impermeable NHS-biotin analog. The biotinylated proteins were precipitated with streptavidin-coated beads, and the precipitate (Ppt) and supernatant (Sup) were analyzed by Western blot. All of the pellet and 1/10 of the supernatant were loaded. AS 472 showed the presence of Nogo-A in the precipitated sample, whereas the intracellular proteins $\beta$-tubulin and BiP were not present in the precipitated material. Intracellular Nogo-A, $\beta$-tubulin, and BiP were found in the supernatant.

specific. AS Bianca recognizing the N-terminus of Nogo-A, but not the corresponding preimmune serum, also stained the cell surface of living oligodendrocytes (Fig. $7 i, k$ ). Staining with AS 922 showed that also the Nogo-66 region is exposed on the surface of oligodendrocytes, confirming previous reports (GrandPré et al., 2000). Because AS 922 stains additional bands on Western blot (Fig. $1 B$ ), however, we cannot exclude the possibility that the antiserum also recognizes proteins other than Nogo on the cell surface of oligodendrocytes. Cell surface staining was present on all major and small processes and on the cell body.

These results suggest that the Nogo-A-specific part and the $\mathrm{N}$-terminus of the molecule as well as the Nogo-66 loop are exposed to the extracellular space on the plasma membrane of oligodendrocytes.

\section{Cell surface biotinylation of Nogo-A}

To confirm the presence of Nogo-A on the cell surface of oligodendrocytes, living, unpermeabilized cultures of newborn rat brain oligodendrocytes were exposed to a membraneimpermeable biotinylating reagent. Biotinylated proteins were precipitated with streptavidin-coated beads. The precipitated proteins and the supernatants of the precipitates were analyzed by Western blot. In the precipitate, Nogo-A was recognized by the Nogo-A-specific AS 472 with the expected molecular weight of $190 \mathrm{kDa}$ (Fig. 8). This band was also recognized by another anti-Nogo-A antiserum, AS Bruna (data not shown) and was not detected when biotin was omitted in control experiments (data not shown). The abundant intracellular proteins $\beta$-tubulin and
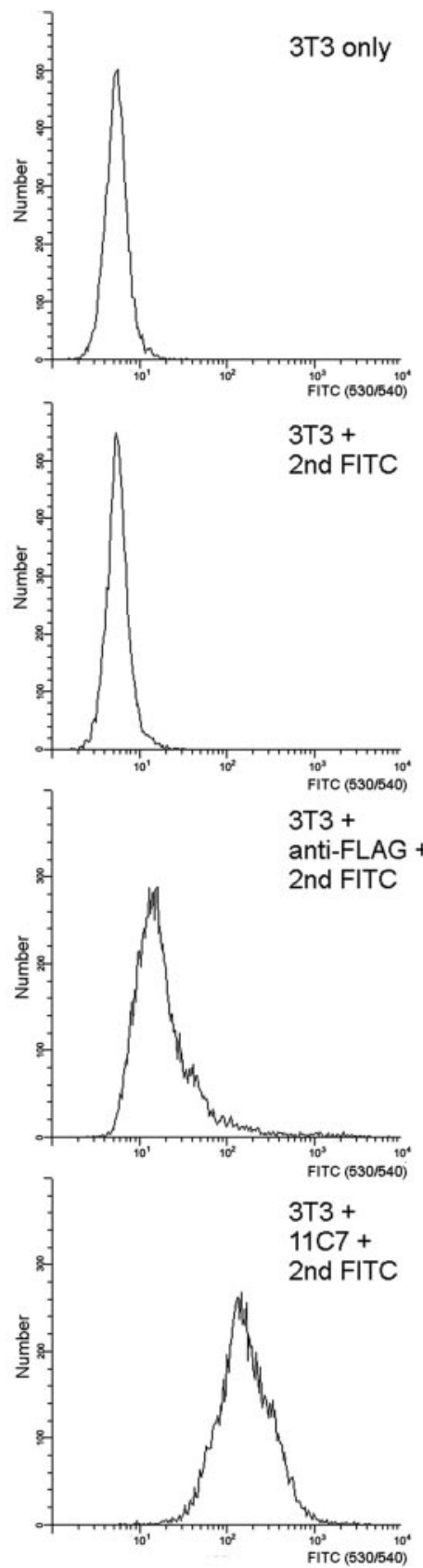

Figure 9. Nogo-A-specific epitopes are detected at the cell surface of $3 T 3$ fibroblasts. $3 T 3$ fibroblasts were detached with Cell Dissociating Buffer (Invitrogen) and incubated with $11 \mathrm{C7}$ ( $\alpha$-Nogo-A) at a concentration of $0.1 \mu \mathrm{m}$ for $1 \mathrm{hr}$. As an isotype control, the $\alpha$-FLAG-M2 antibody is used at a concentration of $0.1 \mu \mathrm{m}$. After washing twice with PBS, the cells were incubated with a goat $\alpha$-mouse FITC-labeled antibody (1:100) and analyzed by flow cytometry. Additional negative controls include unstained $3 \mathrm{~T} 3$ fibroblasts and the secondary antibody alone. In all experiments dead cells were detected by Via-Probe (BD-PharMingen) and are excluded from the analysis. Note that the $11 C 7$ antibody detects the Nogo-A-specific region on intact, unpermeabilized $3 \mathrm{~T} 3$ fibroblasts.

$\mathrm{BiP}$ were not present in the precipitated material but were detected in the supernatant (Fig. 8). In line with the data shown below (see Fig. 10), large amounts of Nogo-A were also present intracellularly. Densitometric analysis of blots of three separate experiments revealed that $\sim 1 \%$ of total cellular Nogo-A could be precipitated by biotinylation from the cell surface of the cultured oligodendrocytes. 

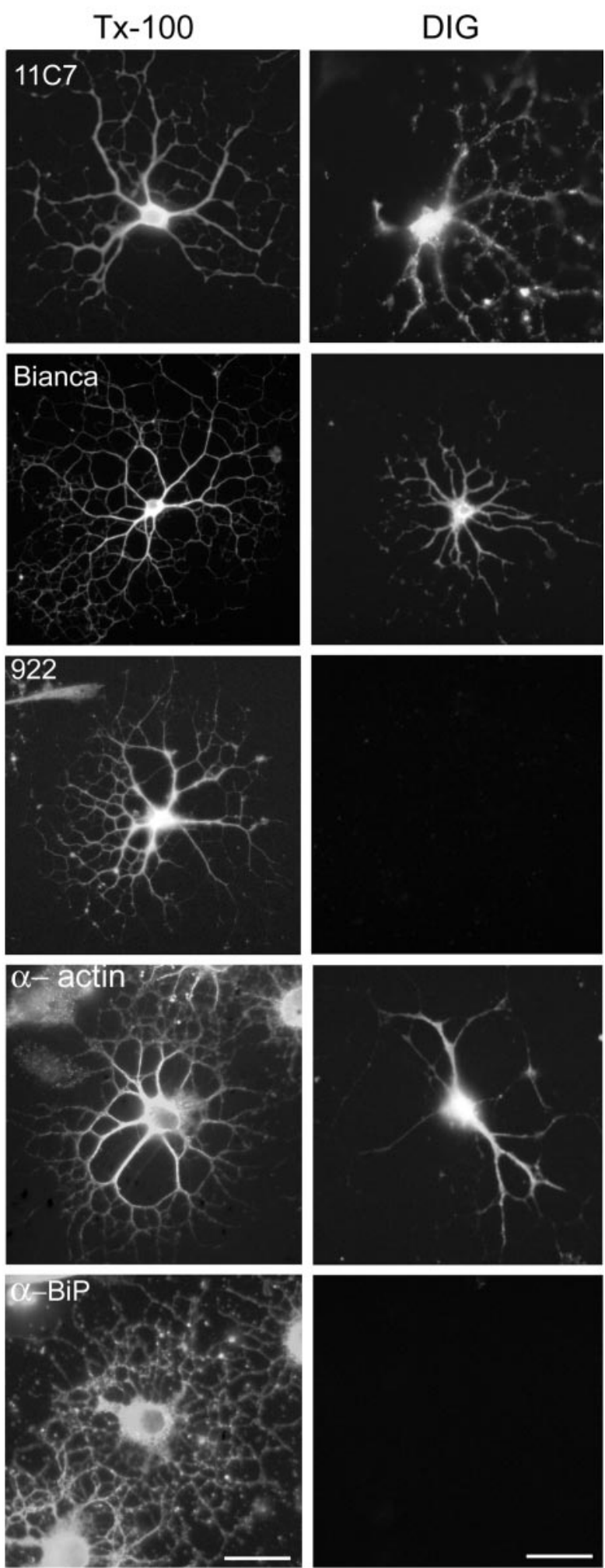

Figure 10. Topology of Nogo-A in cultured oligodendrocytes. Oligodendrocytes ( $3-5 \mathrm{~d}$ in culture) were either fixed and completely permeabilized with Triton X-100 (TX-100) or only plasma membrane permeabilized with digitonin (DIG). Cells were incubated with different $\alpha$-Nogo-A antibodies. All $\alpha$-Nogo-A Abs, mAb 11C7, AS Bianca, and AS 922 specifically recognize oligodendrocytes in dissociated rat optic nerve cultures (left row). After selective permeabilization with DIG, mAb 11C7, AS Bianca, and $\alpha$-actin IgM mAb stain Nogo in the cytoplasm of oligodendrocytes (right row), whereas AS 922 does not. Antibodies against the luminal ER protein BiP were used as a control for the selective permeabilization. In DIG-permeabilized cells, no $\alpha$-BiP staining could be detected, whereas all cells were strongly stained in the Tx-100permeabilized cultures. Scale bar, $30 \mu \mathrm{m}$.
Nogo-A is present at the surface of $3 \mathrm{~T} 3$ fibroblasts with NogoA-specific regions facing the extracellular space

Nogo-A is expressed endogenously in various cultured cell lines including the Nogo-A-responsive 3T3 fibroblasts (as shown by RT-PCR and Western blot) (Oertle et al., 2003b). To analyze whether Nogo-A-specific regions are also present on the surface of these cells, 3T3 fibroblasts were detached from the culture flask with Cell Dissociation Solution and incubated in suspension with $0.1 \mu \mathrm{M}$ Nogo-A-specific mAb 11C7, followed by FITC-conjugated secondary Ab. Cells that bound the Nogo-A antibody were separated from unlabeled cells by fluorescence-activated cell sorting. mAb 11C7, but not a mouse IgG control $\mathrm{Ab}$ or the secondary $\mathrm{Ab}$ alone, labeled the $3 \mathrm{~T} 3$ cells as seen by a large shift of the fluorescence intensity of the 3 T3 cell population (Fig. 9).

This result indicates that the mAb 11C7 epitope, aa 623640, which lies within the Nogo-A-specific region with highest inhibitory activity, is present on the surface of living 3T3 fibroblasts.

\section{Intracellular localization and topology of Nogo-A}

Fixed and permeabilized oligodendrocytes in cultures derived from P7-P10 optic nerve were stained with AS 472, AS 922, AS Bianca, and the mAbs 11C7, 11A8, and 3D11 (Fig. 10). The bulk of the staining was reticular, present in both the cell body and the large processes of the oligodendrocytes. Note the difference in staining between Nogo-A (Fig. 10, 11C7 Tx-100), an ER membrane protein, and $\mathrm{BiP}$ (Fig. 10, $\alpha$ - $\mathrm{BiP} \mathrm{Tx}-100$ ), which is a soluble protein present in the ER lumen. (The same reticular staining patterns were obtained with calnexin, also an ER membrane protein) (Fig. $11 \mathrm{~A}-\mathrm{C}$ ). Nogo-A was not detectable on the membrane sheaths formed between the fine processes at longer culture times (data not shown). To elucidate the orientation of the intracellular protein, we selectively permeabilized oligodendrocytes with digitonin (DIG), an agent that at low concentrations permeabilizes solely the plasma membrane and leaves intracellular membranes intact (De Strooper et al., 1997). In cultures permeabilized with DIG, all antibodies and antisera except for AS 922 stained Nogo-A in the cytoplasm of oligodendrocytes (Fig. 10, right row). Staining with an antibody against a lumenal ER protein, BiP, was negative (Fig. 10), whereas staining against actin was positive (Fig. 10), showing the selectivity of the plasma membrane, but not ER, permeabilization.

These results demonstrate that the Nogo-A-specific region and the $\mathrm{N}$-terminus of Nogo-A are exposed to the cytoplasmic side of intracellular membranes, at least for a large part of the Nogo-A residing in the ER.

We then examined in which intracellular compartment Nogo-A was present by colocalization studies using confocal microscopy. Double labeling with antibodies against Nogo-A and the ER marker calnexin (Fig. $11 A-C$ ) revealed that most but not all Nogo-A colocalized with calnexin. The colocalization was most marked in the oligodendrocyte processes. In the cell body, an area could often be observed to one side of the nucleus where only Nogo-A was present but the ER marker was absent (Fig. 11C, arrowhead). In this perinuclear region, Nogo-A colocalized with the Golgi marker MG160 (Gonatas et al., 1989; Croul et al., 1990; Gonatas et al., 1995) (Fig. $11 D-F$ ). Thus, Nogo-A is present intracellularly in both the ER and the Golgi complex. 

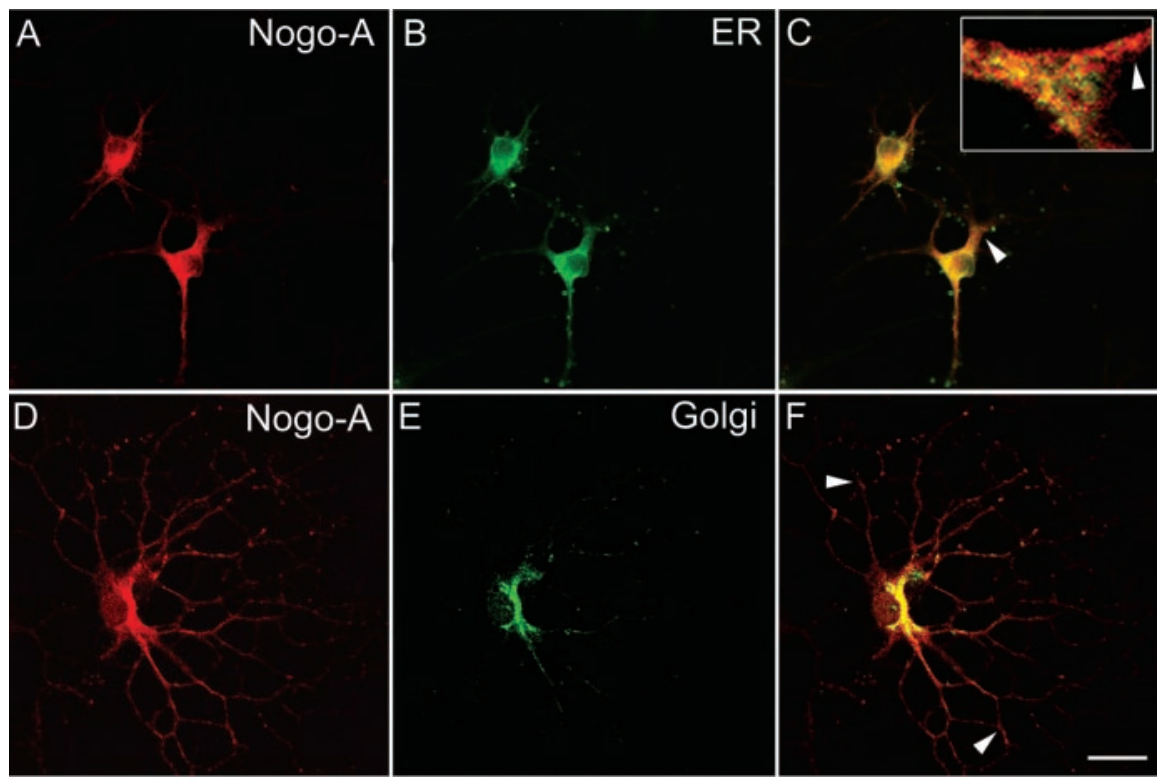

Figure 11. Intracellular localization of Nogo-A in cultured oligodendrocytes. Fixed oligodendrocytes permeabilized with Triton X-100 were double stained with mAb $11 C 7(A$, red) and the ER marker $\alpha$-calnexin ( $B$, green) or AS $472(D$, red) and $\alpha$-MG160 outlining the Golgi complex ( $E$, green) and analyzed by confocal microscopy in single optical sections. Nogo-A colocalizes with calnexin $(C$, yellow) as well as with the Golgi-marker ( $F$, yellow). The magnification in $C$ is taken from a different cell. The planes of the optical sections were chosen for optimal visualization of the colocalization of Nogo with the marker proteins in the cell body and the main processes. Both $\mathrm{mAb} 11 \mathrm{C}$ and AS 472 stain the entire cell with all the processes. Note the regions in which the Nogo-A immunoreactivity does not completely overlap with the ER-marker ( $C$, arrowheads) or Golgi-marker ( $F$, arrowheads). Scale bar: (in F) A-C, $20 \mu \mathrm{m} ; D-F, 15 \mu \mathrm{m}$.

\section{Discussion}

Three domains of Nogo-A are differentially involved in the inhibition of cell spreading, neurite outgrowth, and growth cone collapse

More than 50 Nogo protein fragments were expressed in E. coli or eukaryotic cells and coated as culture substrates or added as soluble proteins to cultured cells. Three active regions of Nogo could be defined. (1) On the basis of our semiquantitative analysis, the $\mathrm{N}$-terminus of Nogo-A/-B inhibits 3T3 cell spreading as a substrate but has only a minor effect on neurons. (2) The Nogo-Aspecific region and its central 181 amino acids are an inhibitory substrate for primary neurons, PC12 cells, and fibroblasts, and the same regions induce growth cone collapse when added as dimers in solution. (3) Dimeric Nogo-66 (loop region between the two C-terminal hydrophobic regions) induces growth cone collapse, but Nogo-66 or Nogo-C coated as substrate are inhibitory for neither E7-E9 chick retina or PC12 cell neurite outgrowth nor fibroblast spreading. Thus, Nogo-66 peptide seems to be prime facie more potent than the Nogo-A-specific region in inducing DRG growth cone collapse, whereas the Nogo-Aspecific region has a stronger neurite outgrowth inhibitory activity. This might indicate that the interaction of Nogo-66 with its receptor NgR could be involved primarily in axonal guidance, whereas the Nogo-A-specific region could be involved in limiting plasticity and regeneration. It is known from other proteins that multiple distinct regions might contribute to their inhibitory activity (Ughrin et al., 2003).

The potent inhibitory activity of the Nogo-A regions has been recognized previously (Chen et al., 1999, 2000; Oertle et al., 2000; Prinjha et al., 2000; Fournier et al., 2001). The physiological importance of this region is emphasized by the fact that an antiserum (AS 472) against aa 623-640 in the Nogo-A-specific region neutralizes the inhibitory activity of CNS myelin in vitro (Chen et al., 2000) and induces sprouting of adult rat Purkinje axons in vivo (Buffo et al., 2000). A contribution of the aa 763-865 region $(\mathrm{NiG}-\Delta 19)$ to the inhibitory activity in vivo is emphasized by recent findings showing that pump-infused mAb 7B12, which binds to an epitope within NiG$\Delta 19$, leads to compensatory axonal sprouting along with improved functional recovery after experimental stroke in adult rats (Wiessner et al., 2003). On the other hand, the role of Nogo-B and Nogo-C (both containing Nogo-66), which have a broad expression pattern in peripheral tissues as shown by Northern and Western blots (Morris et al., 1999; Tagami et al., 2000; Huber et al., 2002), is still unclear.

The Nogo-A-specific region has an inhibitory effect on a range of cells including neurons, 3T3 fibroblasts, and $\mathrm{CHO}$ cells. Nogo-A, which is predominantly present in oligodendrocytes and myelin in the adult CNS, may therefore not only restrict neurite growth, plasticity, and axonal regeneration, but also limit the invasion and migration of cells and tumors in the CNS (Amberger et al., 1998; Belien et al., 1999). The presence of Nogo-A in various cell lines in vitro (Oertle et al., 2003b), and on the surface of 3T3 fibroblast cells in particular, may suggest an additional role, e.g., in the context of cell contact-mediated growth control.

All of these results suggest that the Nogo-A molecule possesses several binding sites (at least two for fibroblasts and neurons, respectively) and that the Nogo receptor is possibly a complex composed of several different subunits. One such subunit, NgR, serves as receptor component for the Nogo-66 peptide (Fournier et al., 2001), OMgp (Wang et al., 2002a), and MAG (Domeniconi et al., 2002; Liu et al., 2002). Being a GPI-anchored protein, it requires additional subunits for signal transduction. The bioactive Nogo-A-specific regions bind efficiently to the surface of 3T3 fibroblasts and to rat brain membranes, hence strongly suggesting the presence of Nogo-A-specific receptor(s). Our data demonstrate that the Nogo-A-mediated inhibition of cell spreading can occur in the absence of $\mathrm{NgR}$ and that the presence of $\mathrm{NgR}$ does not change the responsiveness of $\mathrm{CHO}$ cells to Nogo-66 or Nogo-A.

Activation of the small GTPase RhoA has been shown to be a crucial step in the signal transduction of inhibitory cues in various neurons (Li et al., 2002; Winton et al., 2002). The Nogo-66 peptide can activate Rho-A (Niederost et al., 2002), probably via activation of the $\mathrm{NgR}$ coreceptor p75 ${ }^{\mathrm{NTR}}$ (Wang et al., 2002b). Interestingly, the Nogo-A fragments aa 174-979 (NiG) and aa $544-725$ (NiG- $\Delta 20)$ have been shown to also activate RhoA and inhibit Rac in cerebellar granule cells and 3T3 fibroblasts (Niederost et al., 2002), and this still occurs after removal of $\mathrm{NgR}$ by phosphoinositide-specific phospholipase $\mathrm{C}$ treatment. These results suggest that RhoA activation is a key downstream component for both NgR and the putative Nogo-A-specific receptor.

Heteromeric receptor complexes interacting with different binding sites of a given ligand are well known for axonal guidance molecules [e.g., plexins and neuropilins for semaphorins (Tama- 
gnone et al., 1999)] as well as for neurotrophic factors [e.g., tropomyosin related kinases and p75 neurotrophin receptor (p75 ${ }^{\mathrm{NTR}}$ ) for neurotrophins (Lee et al., 2001)] and inhibitory proteins [e.g., p75, NgR and gangliosides for MAG (Domeniconi et al., 2002; Liu et al., 2002; Vyas et al., 2002; Yamashita et al., 2002]. Whether the specificity of the response to Nogo (growth inhibition vs growth cone collapse; cell type specificities) is linked to specific binding sites and receptor subunits remains to be investigated.

\section{Inhibitory regions of Nogo-A are exposed at the cell surface of oligodendrocytes}

Several lines of evidence suggest the presence of large parts of Nogo-A, including the inhibitory regions at the cell surface facing the extracellular space. These include cell surface biotinylation, immunocytochemistry on living cultured oligodendrocytes with three antisera and four monoclonal antibodies, all against different parts of Nogo-A, and cell sorting of surface-labeled $3 \mathrm{~T} 3$ fibroblasts. The presence of Nogo-A at the cell surface of oligodendrocytes in vitro is consistent with results obtained in vivo: sprouting of axons can be elicited in intact regions of the adult rat CNS by application of AS 472 or mAb 7B12 (Buffo et al., 2000; Wiessner et al., 2003).

Nevertheless, a high proportion of Nogo-A protein was found intracellularly, associated with ER and Golgi membranes. In transfected cell lines such as COS or CHO cells, ectopically expressed Nogo is also localized in the ER and Golgi and was not detected on the cell surface (data not shown). Interestingly, Nogo-A was detected on the cell surface only in differentiated oligodendrocytes, but intracellular Nogo-A was present also in oligodendrocyte precursors (Wang et al., 2002c) (our unpublished observations). This is in agreement with the observation that the contact-mediated inhibition exerted by cultured oligodendrocytes was not detectable in precursor cells (Schwab and Caroni, 1988; Bandtlow et al., 1990). In addition, intracellular Nogo-A released to the extracellular matrix after oligodendrocyte and myelin damage might contribute to the inhibition of axonal regeneration as has been proposed previously (Goldberg and Barres, 2000).

Permeabilization of only the plasma membrane of oligodendrocytes before addition of antibodies revealed that the Nogo-Aspecific sequences that face the extracellular space at the plasma membrane can also be exposed at the cytoplasmic side of intracellular Nogo. This would support the hypothesis that Nogo-A exists in at least two different membrane topologies in oligodendrocytes. The topogenic contribution of the unusually long hydrophobic domains ( 35 and 36 aa) is thought to be important for this uncommon membrane orientation of the Nogo proteins. It is unclear whether Nogo-A that is present at the cell surface of oligodendrocytes is translocated in the ER in two different orientations or whether it changes its topology at a later stage, e.g., in the Golgi or at the plasma membrane, analogous to certain viral envelope glycoproteins of hepatitis B and C virus (Ostapchuk et al., 1994; Cocquerel et al., 2002).

Nogo-A has no signal sequence. As an alternative, many unconventional membrane proteins can use internal hydrophobic sequences as signal anchor (Goder and Spiess, 2001); for Nogo-A this could be one of the C-terminal transmembrane domains. The N-terminal domain would then be translocated only after synthesis has been completed, as has been described for other proteins (Lu et al., 1998; Monne et al., 1999; Nilsson et al., 2000; Goder and Spiess, 2001; Cocquerel et al., 2002). It is also possible that Nogo-A reaches the cell surface by a nonconventional path- way, for example by inserting directly into the plasma membrane. For several proteins that have been shown to exhibit more than one topological orientation, such as P-glycoprotein, ductin, cytochrome $\mathrm{P} 450$, microsomal epoxide hydrolase, or prion protein, the different topological forms can result in protein targeting to different cellular compartments or correlate with multiple biological functions (for review, see Levy, 1996; Hegde et al., 1998).

Cell-surface Nogo-A comprises $\sim 1 \%$ of the total cellular Nogo-A. The large intracellular pool of Nogo-A present in oligodendrocytes may represent an unprocessed precursor form [as for cystic fibrosis transmembrane regulator (CFTR)] (Lu et al., 1998) and/or may have an intracellular, additional function as for, e.g., members of the $S 100$ protein family (for review, see Donato, 1999), CFTR (Bradbury, 1999), and the inositol 1,4,5trisphosphate receptor (Cunningham et al., 1993; Bush et al., 1994; Mayrleitner et al., 1995; Quinton and Dean, 1996; Tanimura et al., 2000).

Additional studies are required to unequivocally demonstrate the herein proposed surface exposure of Nogo-A-specific and Nogo-66 epitopes. Moreover, the identification of the exact topology of the two large C-terminal hydrophobic regions, e.g., by TROSY-based nuclear magnetic resonance (Fernandez et al., 2001), could further clarify our model of two different membrane orientations of Nogo-A.

In summary, our data demonstrate that the Nogo-A-specific part of the molecule has neurite growth inhibitory properties in vitro, and we propose that it is present at the cell surface of certain cells. Different stretches of Nogo-A contribute to this inhibitory activity. The Nogo-A-specific stretches are shown to bind to the surface of responsive cells and brain cortical membranes, suggesting the presence of new, so far unknown, Nogo-A-specific receptor(s) functioning independently of or in a complex with the Nogo-66 receptor NgR. Results from several experiments indicate that Nogo-A can have at least two different membrane topologies, pointing to the possibility of multiple functions both at the cell surface and intracellularly. The data presented here contribute to the understanding of the mechanisms underlying Nogo-mediated neurite growth inhibition and provide important information for the identification of new interacting molecules (receptors, intracellular binding partners) involved in Nogo processing and signaling.

\section{References}

Amberger VR, Hensel T, Ogata N, Schwab ME (1998) Spreading and migration of human glioma and rat $\mathrm{C} 6$ cells on central nervous system myelin in vitro is correlated with tumor malignancy and involves a metalloproteolytic activity. Cancer Res 58:149-158.

Bandtlow CE, Löschinger J (1997) Developmental changes in neuronal responsiveness to the CNS myelin-associated neurite growth inhibitor NI35/250. Eur J Neurosci 9:2743-2752.

Bandtlow CE, Zachleder T, Schwab ME (1990) Oligodendrocytes arrest neurite growth by contact inhibition. J Neurosci 10:3837-3848.

Bandtlow CE, Schmidt MF, Hassinger TD, Schwab ME, Kater SB (1993) Role of intracellular calcium in NI-35-evoked collapse of neuronal growth cones. Science 259:80-83.

Behar O, Mizuno K, Neumann S, Woolf CJ (2000) Putting the spinal cord together again. Neuron 26:291-293.

Belien ATJ, Paganetti PA, Schwab ME (1999) Membrane-type 1 matrix metalloprotease (MT1-MMP) enables invasive migration of glioma cells in central nervous system white matter. J Cell Biol 144:373-383.

Bradbury NA (1999) Intracellular CFTR: localization and function. Physiol Rev 79:175-191.

Buffo A, Zagrebelsky M, Huber AB, Skerra A, Schwab ME, Strata P, Rossi F (2000) Application of neutralizing antibodies against NI-35/250 myelinassociated neurite growth inhibitory proteins to the adult rat cerebellum 
induces sprouting of uninjured Purkinje cell axons. J Neurosci 20:2275-2286.

Bush KT, Stuart RO, Li SH, Moura LA, Sharp AH, Ross CA, Nigam SK (1994) Epithelial inositol 1,4,5-trisphosphate receptors. Multiplicity of localization, solubility, and isoforms. J Biol Chem 269:23694-23699.

Caroni P, Schwab ME (1988) Two membrane protein fractions from rat central myelin with inhibitory properties for neurite growth and fibroblast spreading. J Cell Biol 106:1281-1288.

Chen MS, Schnell L, van der Haar ME, Oertle T, Schwab ME (1999) Inhibitory activity and domain(s) of the myelin protein Nogo-A. Soc Neurosci Abstr 25:2030.

Chen MS, Huber AB, van der Haar ME, Frank M, Schnell L, Spillmann AA, Christ F, Schwab ME (2000) Nogo-A is a myelin-associated neurite outgrowth inhibitor and an antigen for monoclonal antibody IN-1. Nature 403:434-439.

Cocquerel L, Op dB, Lambot M, Roussel J, Delgrange D, Pillez A, Wychowski C, Penin F, Dubuisson J (2002) Topological changes in the transmembrane domains of hepatitis $\mathrm{C}$ virus envelope glycoproteins. EMBO J 21:2893-2902.

Croul S, Mezitis SG, Stieber A, Chen YJ, Gonatas JO, Goud B, Gonatas NK (1990) Immunocytochemical visualization of the Golgi apparatus in several species, including human, and tissues with an antiserum against MG160, a sialoglycoprotein of rat Golgi apparatus. J Histochem Cytochem 38:957-963.

Cunningham AM, Ryugo DK, Sharp AH, Reed RR, Snyder SH, Ronnett GV (1993) Neuronal inositol 1,4,5-trisphosphate receptor localized to the plasma membrane of olfactory cilia. Neuroscience 57:339-352.

De Strooper B, Beullens M, Contreras B, Levesque L, Craessaerts K, Cordell B, Moechars D, Bollen M, Fraser P, George-Hyslop PS, Van Leuven F (1997) Phosphorylation, subcellular localization, and membrane orientation of the Alzheimer's disease-associated presenilins. J Biol Chem 272:3590-3598.

Domeniconi M, Cao Z, Spencer T, Sivasankaran R, Wang KC, Nikulina E, Kimura N, Cai H, Deng K, Gao Y, He Z, Filbin MT (2002) Myelinassociated glycoprotein interacts with the Nogo66 receptor to inhibit neurite outgrowth. Neuron 35:283-290.

Donato R (1999) Functional roles of S100 proteins, calcium-binding proteins of the EF-hand type. Biochim Biophys Acta 1450:191-231.

Fernandez C, Adeishvili K, Wuthrich K (2001) Transverse relaxationoptimized NMR spectroscopy with the outer membrane protein OmpX in dihexanoyl phosphatidylcholine micelles. Proc Natl Acad Sci USA 98:2358-2363.

Flanagan JG, Leder P (1990) The kit ligand: a cell surface molecule altered in steel mutant fibroblasts. Cell 63:185-194.

Fournier AE, GrandPre T, Strittmatter SM (2001) Identification of a receptor mediating Nogo-66 inhibition of axonal regeneration. Nature 409:341-346.

Fritsche J, Reber BFX, Schindelholz B, Bandtlow CE (1999) Differential cytoskeletal changes during growth cone collapse in response to hSemall and thrombin. Mol Cell Neurosci 14:398-418.

Goder V, Spiess M (2001) Topogenesis of membrane proteins: determinants and dynamics. FEBS Lett 504:87-93.

Goldberg JL, Barres BA (2000) Nogo in nerve regeneration. Nature 403:369-370.

Gonatas JO, Mezitis SG, Stieber A, Fleischer B, Gonatas NK (1989) MG-160. A novel sialoglycoprotein of the medial cisternae of the Golgi apparatus. J Biol Chem 264:646-653.

Gonatas JO, Mourelatos Z, Stieber A, Lane WS, Brosius J, Gonatas NK (1995) MG-160, a membrane sialoglycoprotein of the medial cisternae of the rat Golgi apparatus, binds basic fibroblast growth factor and exhibits a high level of sequence identity to a chicken fibroblast growth factor receptor. J Cell Sci 108:457-467.

GrandPré T, Nakamura F, Vartanian T, Strittmatter SM (2000) Identification of the Nogo inhibitor of axon regeneration as a reticulon protein. Nature 403:439-444.

Hegde RS, Mastrianni JA, Scott MR, DeFea KA, Tremblay P, Torchia M, DeArmond SJ, Prusiner SB, Lingappa VR (1998) A transmembrane form of the prion protein in neurodegenerative disease. Science 279:827-834.

Huber AB, Weinmann O, Brosamle C, Oertle T, Schwab ME (2002) Patterns of nogo mRNA and protein expression in the developing and adult rat and after CNS lesions. J Neurosci 22:3553-3567.
Kaupmann K, Huggel K, Heid J, Flor PJ, Bischoff S, Mickel SJ, McMaster G, Angst C, Bittiger H, Froestl W, Bettler B (1997) Expression cloning of $\mathrm{GABA}(\mathrm{B})$ receptors uncovers similarity to metabotropic glutamate receptors. Nature 386:239-246.

Kelleher DJ, Kreibich G, Gilmore R (1992) Oligosaccharyltransferase activity is associated with a protein complex composed of ribophorins I and II and a $48 \mathrm{kd}$ protein. Cell 69:55-65.

Lee FS, Kim AH, Khursigara G, Chao MV (2001) The uniqueness of being a neurotrophin receptor. Curr Opin Neurobiol 11:281-286.

Levy D (1996) Membrane proteins which exhibit multiple topological orientations. Essays Biochem 31:49-60.

Li X, Saint CP, Aktories K, Lamarche-Vane N (2002) Rac1 and Cdc42 but not RhoA or Rho kinase activities are required for neurite outgrowth induced by the Netrin-1 receptor DCC (deleted in colorectal cancer) in N1E-115 neuroblastoma cells. J Biol Chem 277:15207-15214.

Liu BP, Fournier A, GrandPre T, Strittmatter SM (2002) Myelin-associated glycoprotein as a functional ligand for the nogo-66 receptor. Science 297:1190-1193.

Loschinger J, Bandtlow CE, Jung J, Klostermann S, Schwab ME, Bonhoeffer F, Kater SB (1997) Retinal axon growth cone responses to different environmental cues are mediated by different second-messenger systems. J Neurobiol 33:825-834.

Lu Y, Xiong X, Helm A, Kimani K, Bragin A, Skach WR (1998) Co- and posttranslational translocation mechanisms direct cystic fibrosis transmembrane conductance regulator $\mathrm{N}$ terminus transmembrane assembly. J Biol Chem 273:568-576.

Mayrleitner M, Schafer R, Fleischer S (1995) IP3 receptor purified from liver plasma membrane is an $(1,4,5)$ IP 3 activated and $(1,3,4,5)$ IP 4 inhibited calcium permeable ion channel. Cell Calcium 17:141-153.

Merril CR, Dunau ML, Goldman D (1981) A rapid sensitive silver stain for polypeptides in polyacrylamide gels. Anal Biochem 110:201-207.

Monne M, Gafvelin G, Nilsson R, von Heijne G (1999) N-tail translocation in a eukaryotic polytopic membrane protein: synergy between neighboring transmembrane segments. Eur J Biochem 263:264-269.

Moreira EF, Jaworski CJ, Rodriguez IR (1999) Cloning of a novel member of the reticulon gene family (RTN3): gene structure and chromosomal localization to 11q13. Genomics 58:73-81.

Morris NJ, Ross SA, Neveu JM, Lane WS, Lienhard GE (1999) Cloning and characterization of a $22 \mathrm{kDa}$ protein from rat adipocytes: a new member of the reticulon family. Biochim Biophys Acta 1450:68-76.

Niederöst B, Zimmermann DR, Schwab ME, Bandtlow CE (1999) Bovine CNS myelin contains neurite growth-inhibitory activity associated with chondroitin sulfate proteoglycan. J Neurosci 19:8979-8989.

Niederost B, Oertle T, Fritsche J, McKinney RA, Bandtlow CE (2002) Nogo-A and myelin-associated glycoprotein mediate neurite growth inhibition by antagonistic regulation of RhoA and Racl. J Neurosci 22:10368-10376.

Nilsson I, Witt S, Kiefer H, Mingarro I, von Heijne G (2000) Distant downstream sequence determinants can control $\mathrm{N}$-tail translocation during protein insertion into the endoplasmic reticulum membrane. J Biol Chem 275:6207-6213.

Oertle T, Bandtlow CE, Schwab ME (2000) Characterization of the gene structure and the inhibitory regions of Nogo-RTN4. Soc Neurosci Abstr 26:573.

Oertle T, Merkler D, Schwab ME (2003a) Do cancer cells die because of Nogo-B? Oncogene 22:1390-1399.

Oertle T, Huber C, van der Putten H, Schwab ME (2003b) Genomic structure and functional characterisation of the promoters of human and mouse Nogo/Rtn-4. J Mol Biol 325:299-323.

Oertle T, Klinger M, Stuermer CAO, Schwab ME (2003c) A reticular rhapsody: phylogenic evolution and nomenclature of the RTN/Nogo gene family. FASEB J, in press.

Olpe HR, Karlsson G, Pozza MF, Brugger F, Steinmann M, Van Riezen H, Fagg G, Hall RG, Froestl W, Bittiger H (1990) CGP 35348: a centrally active blocker of GABAB receptors. Eur J Pharmacol 187:27-38.

Ostapchuk P, Hearing P, Ganem D (1994) A dramatic shift in the transmembrane topology of a viral envelope glycoprotein accompanies hepatitis B viral morphogenesis. EMBO J 13:1048-1057.

Prinjha R, Moore SE, Vinson M, Blake S, Morrow R, Christie G, Michalovich D, Simmons DL, Walsh FS (2000) Inhibitor of neurite outgrowth in humans. Nature 403:383-384.

Quinton TM, Dean WL (1996) Multiple inositol 1,4,5-trisphosphate recep- 
tor isoforms are present in platelets. Biochem Biophys Res Commun 224:740-746.

Roebroek AJM, van de Velde HJK, Van Bokhoven A, Broers JLV, Ramaekers FCS, Van de Ven WJM (1994) Cloning and expression of alternative transcripts of a novel neuroendocrine-specific gene and identification of its 135-kDa translational product. J Biol Chem 268:13439-13447.

Roebroek AJ, Contreras B, Pauli IG, Van de Ven WJ (1998) cDNA cloning, genomic organization, and expression of the human RTN2 gene, a member of a gene family encoding reticulons. Genomics 51:98-106.

Rubin BP, Spillmann AA, Bandtlow CE, Keller F, Schwab ME (1995) Inhibition of PC12 cell attachment and neurite outgrowth by detergent solubilized CNS myelin proteins. Eur J Neurosci 7:2524-2529.

Schmalfeldt M, Bandtlow CE, Dours-Zimmermann MT, Winterhalter KH, Zimmermann DR (2000) Brain derived versican V2 is a potent inhibitor of axonal growth. J Cell Sci 113:807-816.

Schwab ME, Bartholdi D (1996) Degeneration and regeneration of axons in the lesioned spinal cord. Physiol Rev 76:319-370.

Schwab ME, Caroni P (1988) Oligodendrocytes and CNS myelin are nonpermissive substrates for neurite growth and fibroblast spreading in vitro. J Neurosci 8:2381-2393.

Spillmann AA, Bandtlow CE, Lottspeich F, Keller F, Schwab ME (1998) Identification and characterization of a bovine neurite growth inhibitor (bNI-220). J Biol Chem 273:19283-19293.

Tagami S, Eguchi Y, Kinoshita M, Takeda M, Tsujimoto Y (2000) A novel protein, RTN-XS, interacts with both Bcl-XL and Bcl-2 on endoplasmic reticulum and reduces their anti-apoptotic activity. Oncogene 19:5736-5746.

Tamagnone L, Artigiani S, Chen H, He Z, Ming G, Song H, Chedotal A, Winberg ML, Goodman CS, Poo M-M, Tessier-Lavigne M, Comoglio PM (1999) Plexins are a large family of receptors for transmembrane, secreted, and GPI-anchored semaphorins in vertebrates. Cell 99:71-80.

Tanimura A, Tojyo Y, Turner RJ (2000) Evidence that type I, II, and III inositol 1,4,5-trisphosphate receptors can occur as integral plasma membrane proteins. J Biol Chem 275:27488-27493.

Ughrin YM, Chen ZJ, Levine JM (2003) Multiple regions of the NG2 proteoglycan inhibit neurite growth and induce growth cone collapse. J Neurosci 23:175-186. van de Velde HJK, Roebroek AJ, Senden NH, Ramaekers FC, Van de Ven WJ (1994) NSP-encoded reticulons, neuroendocrine proteins of a novel gene family associated with membranes of the endoplasmic reticulum. J Cell Sci 107:2403-2416.

van der Haar ME, Visser HW, de Vries H, Hoekstra D (1998) Transport of proteolipid protein to the plasma membrane does not depend on glycosphingolipid cotransport in oligodendrocyte cultures. J Neurosci Res 51:371-381

Vielmetter J, Stolze B, Bonhoeffer F, Stuermer CA (1990) In vitro assay to test differential substrate affinities of growing axons and migratory cells. Exp Brain Res 81:283-287.

Vyas AA, Patel HV, Fromholt SE, Heffer-Lauc M, Vyas KA, Dang J, Schachner M, Schnaar RL (2002) Gangliosides are functional nerve cell ligands for myelin-associated glycoprotein (MAG), an inhibitor of nerve regeneration. Proc Natl Acad Sci USA 99:8412-8417.

Wang KC, Koprivica V, Kim JA, Sivasankaran R, Guo Y, Neve RL, He Z (2002a) Oligodendrocyte-myelin glycoprotein is a Nogo receptor ligand that inhibits neurite outgrowth. Nature 417:941-944.

Wang KC, Kim JA, Sivasankaran R, Segal R, He Z (2002b) p75 interacts with the Nogo receptor as a co-receptor for Nogo, MAG and OMgp. Nature 420:74-78.

Wang X, Chun SJ, Treloar H, Vartanian T, Greer CA, Strittmatter SM (2002c) Localization of nogo-a and nogo-66 receptor proteins at sites of axon-myelin and synaptic contact. J Neurosci 22:5505-5515.

Wiessner C, Bareyre FM, Allegrini PR, Mir AK, Frentzel S, Zurini M, Schnell L, Oertle T, Schwab ME (2003) Anti Nogo-A antibody infusion 24 hours after experimental stroke improved behavioral outcome and corticospinal plasticity in normotensive and spontaneously hypertensive rats. J Cereb Blood Flow Metab 23:154-165.

Winton MJ, Dubreuil CI, Lasko D, Leclerc N, McKerracher L (2002) Characterization of new cell permeable C3-like proteins that inactivate Rho and stimulate neurite outgrowth on inhibitory substrates. J Biol Chem 277:32820-32829.

Yamashita T, Higuchi H, Tohyama M (2002) The p75 receptor transduces the signal from myelin-associated glycoprotein to Rho. J Cell Biol 157: $565-570$. 